TI 2015-085/VIII

Tinbergen Institute Discussion Paper
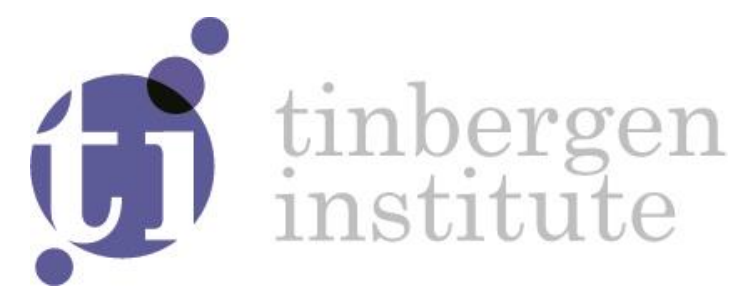

Congestion Pricing in Urban

Polycentric Networks with Distorted

Labor Markets: A Spatial General

Equilibrium Model for the Area

Randstad

Revision

Ioannis Tikoudis ${ }^{1}$

${ }^{1}$ VU Amsterdam; Tinbergen Institute, The Netherlands 
Tinbergen Institute is the graduate school and research institute in economics of Erasmus University Rotterdam, the University of Amsterdam and VU University Amsterdam.

Contact: discussionpapers@tinbergen.nl

More TI discussion papers can be downloaded at http://www.tinbergen.nl

Tinbergen Institute has two locations:

Tinbergen Institute Amsterdam

Gustav Mahlerplein 117

1082 MS Amsterdam

The Netherlands

Tel.: +31(0)205984580

Tinbergen Institute Rotterdam

Burg. Oudlaan 50

3062 PA Rotterdam

The Netherlands

Tel.: +31(0)10408 8900 


\title{
Congestion pricing in urban polycentric networks with distorted labor markets: a spatial general equilibrium model for the area of Randstad
}

\author{
Ioannis Tikoudis
}

Department of Spatial Economics, VU University Amsterdam

and

Environment Directorate, the Organisation for Economic Co-operation and Development (OECD)

\begin{abstract}
This paper examines the properties of taxes applied in the road links of a polycentric network and their interaction with a spatially-invariant tax on labor income. With the use of a theoretical model, the total welfare change from a revenue-neutral swap between the tax in an arbitrary road link and the distortionary labor tax is decomposed into three distinct effects. These are shown to be the network counterparts of the tax-interaction, revenue-recycling and Pigouvian effects of traditional double-dividend theory. Subsequently, these effects are approximated in a numerical version of the model, used to simulate various tax schemes imposed during the peak commuting hours. With the elasticities of labor supply and transport at plausible values, the results suggest that a cut in the distortionary tax, financed by the road tax revenue, is an essential policy element, independent of the applied tax scheme. In the context of a revenue-neutral tax swap, marginal external cost pricing and the flat kilometer tax are shown to be particularly efficient at low rates of the distortionary tax. At high rates, however, a system of cordon tolls around the major employment nodes of the network is shown to be more effective. With the transportation cross-elasticities at the lower bound, the results show that marginal external cost pricing may be welfare-reducing even when its revenue is recycled in a tax cut manner. At the same time, other archetype externality pricing schemes produce gains only in very low levels of the distortionary tax.
\end{abstract}

Keywords: labor tax, externality taxation, tax-interaction, double-dividend, network, general equilibrium

JEL classification: H21, H23, R13, R40, C63, C68

Second-best road taxes in polycentric networks with distorted labor markets 


\section{Introduction}

The taxation of externalities in road networks has received considerable attention in the literature of transport economics during the last decades. To a large extent, that attention was directed to the secondbest issues arising from the implementation of pricing schemes that allow only a subset of the externalitygenerating facilities (e.g. selected road segments in a transportation network) to be taxed. It has been shown in a variety of settings that such partial taxation causes the optimal values of the unconstrained externality taxes to deviate from their Pigouvian levels. ${ }^{1}$ That is, earlier contributions derived optimal taxing rules under partial taxation conditions in stylized networks of parallel routes (e.g. Verhoef et al., 1996) as well as in generic networks (Verhoef, 2002a; Verhoef 2002b; Van Dender, 2004). ${ }^{2}$ A distinct characteristic of a partial taxation scheme is that it is always suboptimal to a Pigouvian tax scheme (i.e. marginal external cost pricing) when relevant distortionary taxes and household heterogeneity are disregarded. In that context, the use of any partial taxation scheme is justified only by the large implementation costs of a Pigouvian tax scheme.

The advances in the theory of double dividend (e.g. Parry, 1995; Bovenberg and de Mooij, 1994; Bovenberg and Goulder, 1996; Goulder et al., 1999; Parry and Bento, 2000) and its transportation branch (Parry and Bento, 2001; Parry and Bento, 2002; Parry, 2002) highlighted another reason for which second-best settings in externality taxation may emerge. ${ }^{3}$ This regards the existence of at least one distortionary tax, with which a corrective tax interacts negatively, i.e. an upward adjustment of the corrective tax erodes the base of the distortionary tax. ${ }^{4}$ To account for that negative tax interaction effect, the optimal value of the corrective tax falls short of its Pigouvian level. In line with this, Parry and Bento (2001) highlighted, in a setting with a single externality, the case of a negative optimal corrective tax. They then juxtaposed the optimal tax against the marginal external cost pricing rule, which was shown to be welfare decreasing.

This paper examines the second-best issues arising in the simultaneous presence of a distortionary tax (e.g. on labor income) and multiple interrelated external effects (e.g. congestion in different road segments) that could be taxed partially or fully. The exact setting involves the introduction of a road pricing scheme in the congested links of a polycentric highway network used by commuters. In this context, a series of interrelated questions are explored: (i) could partial taxation of the external effects be an answer to the welfare loss caused by marginal external cost pricing, when the background distortionary taxation is rigid? (ii) how is the performance of second-best tax rules affected by the extent of the

\footnotetext{
${ }^{1}$ Throughout the entire paper, the term Pigouvian level of a corrective (externality) tax refers to a tax level that is equal to the marginal external cost. For instance, the Pigouvian level of a toll in a road link is a pecuniary charge equal to the marginal external cost of an additional unit of traffic in that link. Also, the term quasi first-best Pigouvian tax refers to an externality tax set to its Pigouvian level despite its optimal value deviates from that. Appendix A provides the definition of all key concepts used in the paper.

${ }^{2}$ Verhoef (2002a; 2002b) offers a general analytical solution for the second-best problem where not all links of a congested network can be charged; an algorithm based on this analytical solution is then tested on a medium size network. Also, van Dender (2004) shows that constraints in network pricing can cause the optimal toll to deviate in a complex way from the marginal external cost of congestion. These contributions assume that residence and job locations, i.e. origins and destinations, are fixed.

${ }^{3}$ Goulder (1995) and Bovenberg (1999) provide excellent reviews of the existing literature in the field.

${ }^{4}$ For a parallel distortion that takes the form of a command-and-control regulation see Kono and Kawaguchi (2016) and Tikoudis et al. (2015b).
} 
background distortion (iii) is a revenue-neutral tax reform involving marginal external cost pricing always welfare increasing?

Answers to these questions may bear significant policy implications. A positive answer to the first question would imply that a system of corrective taxes could generate a Pareto improvement in the absence of any sophisticated revenue-recycling program, which may be administratively infeasible. For instance, revenue-neutral tax reforms often involve a swap between corrective and distortionary taxes. These taxes are set by different authorities and serve various objectives. Similarly, exploring the second question can be particularly useful in the design of realistic second-best pricing schemes for the traffic externalities generated in networks during commuting hours. Finally, an answer to the third question could indicate whether the potential efficiency loss from optimizing the externality taxes exclusively from an environmental viewpoint can always be offset by tax-cut revenue recycling. If that is true, welfare gains can always be obtained just by computing the Pigouvian levels of the corrective taxes right, as long as the revenue from these taxes is used to reduce the distortionary tax. That is important not only because the estimation of interaction effects (and thus of the optimal tax levels) may be cumbersome; as it is illustrated in the results, the optimal externality taxes may reflect the tax interaction effects to such an extent that their primary (corrective) function is completely misaligned with their relative levels.

The contribution of the paper is twofold. At the theoretical level, it extends the theory of double dividend by introducing a series of elements not explored before: unobserved heterogeneity of households, probabilistic discrete-continuous choice, as well as multiple externalities generated from facilities that may function as substitutes or complements. In line with that, the paper derives an analytic formula for the total welfare effect triggered by a marginal adjustment of the externality tax on a link of a congested network. It is shown that this effect consists of the spatial counterparts of three traditional double-dividend effects (Goulder et al. 1999; Bento et al., 2011): the (own) Pigouvian effect, a taxinteraction effect and a revenue-recycling effect. On top of these well-established effects, however, the welfare change is shown to contain two additional components: a cross-Pigouvian effect, which emerges exclusively in settings with multiple externalities, and a redistribution effect, which emerges only in the presence of household heterogeneity and non-constant marginal utility of income.

The former effect stems from the adjustment in the consumption pattern of all dirty commodities, which is triggered by the adjustment of the externality tax. In the context of this paper, the adjustment of the toll in a road link affects the traffic levels and the external effects in the entire transportation network, as some vehicles reoptimize their routes in response to that change. The cross-Pigouvian effect is, then, negative to the extent it redirects vehicles to links where traffic lies above the social optimum, or to the extent it redirects them away from links where traffic lies below that. The existence of a redistribution effect stemming from heterogeneity of seemingly-identical households and income effects has been highlighted earlier in the literature (Anas, 2012; Jacobs and de Mooij, 2015). The proposed formula integrates the effect in a spatial double-dividend context, i.e. it expresses the marginal welfare loss from horizontal revenue recycling when the marginal utility of income varies across seemingly identical households.

At the applied level, the paper contributes by constructing a polycentric general equilibrium model that is tailored to examine, in the context of a realistic network, the interaction effects between the tax on labor income and the road charges during commuting hours. That is, the proposed numerical model expands: (i) the earlier work by Anas and Kim (1996), Anas and Liu (2007), Anas and Hiramatsu (2013) and Rhee et al. (2014), contributions that consider a network structure but disregard the presence of a relevant distortionary tax in the background, and (ii) the earlier work that considered the double-dividend 
without the use of a network structure (Tscharaktsiew and Hirte, 2010; Tikoudis et al., 2015). By considering explicitly a polycentric structure, the model can derive insights on the welfare effects of archetype space-varying pricing schemes (such as systems of cordon tolls around the major cities of the region, a flat kilometer tax, marginal external cost pricing), as well as of other, more tailored, schemes that can be applied in a network.

The numerical application of the model has a clear geographical reference. The area of Randstad is a polycentric urban conglomeration in western Netherlands, which comprises the country's four largest cities (Amsterdam, Utrecht, Rotterdam and The Hague). The region is of considerable economic significance; while it covers only $20 \%$ of the country's land area, at least $40 \%$ of the country's population resides there, and half of the national income is generated within its boundaries. Despite being a prosperous region, it has experienced lower productivity growth compared to other regions in the Netherlands and Europe for a series of years (annually $1.7 \%$ over the period 1995-2005). It is characterized by large commuting flows between zones and severe congestion during the peak hours. The territorial review by OECD (2007) places heavy congestion and the incoherency of public transport system as the most important drivers of this sluggish growth, as approximately $80 \%$ of the traffic jams in the Netherlands in 2005 occurred in Randstad. ${ }^{5}$ The model is calibrated to fit a series of stylized facts characterizing the behavior of the average household (expenditures shares, allocation of time, etc.) and the characteristics of Randstad region: the general spatial layout and network, the population and employment share of each zone, the average commuting speed of modes, modal split, and the relative land rents, housing prices, wages and floor-to-area ratios. The benchmark equilibrium is used to explore the effects of various pricing schemes with revenue retuned lump-sum or in the form of labor tax cuts.

The numerical simulations yield a series of policy-relevant insights. First, with the labor income tax at $40 \%$ and the road tax revenue recycled lump-sum, no archetype pricing scheme during the peak commuting hours is found to generate welfare gains. In addition, marginal external cost pricing is found to be highly detrimental. To shed more light on these findings, the Pigouvian (i.e. abatement) and the taxinteraction effects derived from the theoretical version of the model are approximated numerically. The analysis shows that the former effects dominate in a substantial part of network only when the labor tax is considerably lower (i.e. at 30\%). Pigouvian effects offset the tax-interaction effects in the entire network at tax levels below 20\%. However, at labor income tax rates between $40 \%$ and $60 \%$ the tax-interaction effect dominates in all links of the network, implying that a positively-priced welfare increasing scheme is highly unlikely to exist, unless its revenue is used to reduce the distortionary labor tax.

In contrast, when revenue is recycled lump-sum, all basic pricing schemes are found to generate welfare gains in the entire range of labor income tax rates considered (i.e. 5\% - 60\%). At the benchmark equilibrium, in which labor tax is set to $40 \%$, the optimal revenue-neutral tax swap generates substantial gains that accrue to approximately $0.73 \%$ of after-tax income. Simultaneously, the road tax revenue suffices to finance a considerable cut in the labor income tax rate of approximately 2.2 percentage points. The sensitivity analysis shows that as the initial labor tax rate increases, all externality tax schemes lose efficiency relative to the optimal scheme. The reason is that with a higher labor tax the associated taxinteraction effects grow larger and dominate the Pigouvian and revenue-recycling effects in larger parts of

\footnotetext{
${ }^{5}$ Broersma and van Dijk (2008) use a growth accounting exercise to disentangle the positive contribution of agglomeration from the negative contribution of congestion. Using Dutch regional industry data for the period between 1995 and 2002, they show that the effect of the latter was large enough to outweigh the effect of the former, leading to the observed slow multifactor productivity growth. Other factors identified by OECD (2007) include distortions originating from the housing market, where a series of land-use practices (e.g. density regulations) add burden to the social cost of public transport provision.
} 
the network. In turn, that implies negative optimal charges in more network links. These cannot be implemented with the basic pricing schemes considered in the study, since the latter are constrained to impose only non-negative charges. As the initial labor income tax rate decreases, the optimal level of the externality tax in each link converges to the corresponding marginal external cost of congestion. At the same time the relative efficiency of each pricing scheme converges to levels that are in alignment with earlier findings.

A distinct part of the discussion is dedicated to the welfare effects induced by a system of cordon tolls around the largest employment nodes, i.e. a polycentric extension of a single cordon surrounding the central business district (CBD) of a monocentric area. To some extent, the results corroborate the findings from earlier contributions (Mun et al., 2003; Mun et al., 2005; Verhoef, 2005) indicating that the relative efficiency of the scheme is lower in a polycentric setting. With the labor tax at $10 \%$, a system of cordon tolls (with revenue recycled in the form of tax-cuts) is found to capture $46 \%$ of the welfare gains of the optimal revenue-neutral tax swap. However, the findings highlight another reason for which the relative efficiency of a cordon scheme may be lower in a polycentric setting. That is, tax-interaction effects in a monocentric setting are much more likely to fade out with distance from the central business district. This allows a cordon scheme to tax, eclectically, the most inelastic parts of labor supply, provided that they locate further away from the CBD (Tikoudis et al., 2015a). In a polycentric setting with cross-commuting flows, however, the elasticity of labor supply will display a non-monotonic variation across space. This renders the eclectic taxation of links where tax-interaction effect is low impossible with a system of cordons. In line with this, the relative efficiency of a cordon toll system is found to lie far below that of a flat kilometer tax (i.e. 64\% versus 78\%), a result that differs substantially from earlier findings (Tikoudis et al., 2015) obtained from a monocentric model (respectively, $84 \%$ versus $70 \%$ ).

The last part of the results highlights a surprising finding. When labor supply is highly elastic and the intermodal elasticity of substitution is low, the tax-interaction effect dominates the Pigouvian and the revenue-recycling effect (at the margin of the base equilibrium) in the vast majority of links in the network. Consequently, even if the revenue is used to reduce the labor tax, all archetype schemes fail to generate welfare gains at tax levels above 30\%. Most important, marginal external cost pricing becomes particularly detrimental, i.e. it generates losses even at tax levels below $25 \%$. The result suggests that the optimal type of revenue recycling does not automatically imply that the tax-interaction effects can be ignored. That is, the principle in charge of the design of the externality tax system (e.g. an environment or transportation ministry) cannot fully dedicate itself to getting the Pigouvian levels of the corrective taxes right, even if the revenue from the externality taxes reduces the revenue that has to be raised by distortionary taxation. In the context of this study, such a failure calls for more complex pricing schemes that will, inevitably, subsidize road use in part of the network, especially the segments used by the users with the most inelastic choice of transportation mode (i.e. the users with the lowest accessibility to public transportation).

The paper is organized as follows: Section 2 presents the theoretical model and derives a closedform expression of the various welfare effects stemming from the adjustment of an externality tax in a network; Section 3 presents the expanded, numerical version of the model; Section 4 describes the application of the model and juxtaposes the key characteristics of the benchmark equilibrium against the data used in the calibration of the model; Section 5 presents the findings and a series of policy implications extracted from the accompanying numerical simulations and sensitivity analyses; Section 6 concludes.

Second-best road taxes in polycentric networks with distorted labor markets 


\section{Theoretical model}

The model presented in this section extends the basic general equilibrium framework used in traditional double-dividend contributions, to account for unobserved heterogeneity in preferences, locational selection and a discrete choice between multiple interdependent, externality-generating facilities (e.g. road links). These facilities are organized in a network structure: different combinations of them (e.g. commuting routes) compose sets of mutually-exclusive alternatives, with each one constituting a strict complement to a tax-distorted labor supply.

\subsection{Space, network representation and discrete choice}

Economic activity takes place in an ordered set of $J$ zones (each represented by a single node),J. ${ }^{6}$ Let the ordered subsets $\mathcal{J}_{R}$ and $\mathcal{J}_{W}$ denote the locations that host residences and jobs respectively, with $\mathcal{J}=\mathcal{J}_{R} \cup \mathcal{J}_{W}$. Throughout the text, the subscript $i$ is used to denote an arbitrary zone in the ordered set $\mathcal{J}_{R}$ that serves as a residential node, i.e. $i \in \mathcal{J}_{R}$. Similarly, the subscript $j$ is used to denote an arbitrary zone in the ordered set $\mathcal{J}$ that serves as an employment node, i.e. $j \in \mathcal{J}_{W}$. Every zone is characterized by mixed land-use, in this case $\mathcal{J}_{R} \cap \mathcal{J}_{W}=\mathcal{J}$. Let the set $\mathcal{C}_{O D}=\mathcal{J}_{R} \times \mathcal{J}_{W}$ denote the Cartesian product of sets $\mathcal{J}_{R}$ and $\mathcal{J}_{W}$, i.e. the set that contains all possible pairs of residential and employment locations. Each element $\mathrm{a}_{i j} \in \mathcal{C}_{O D}$ is an origin-destination pair (hereafter, OD pair).

Two arbitrary zones, $s$ and $e$, are neighboring if there is at least one transport link $l_{m}^{(s e)}$ starting at $s$ and ending at $e$, where the subscript $m$ denotes the type of transport network the link belongs to (e.g. road, rail, etc.). For simplicity, it is assumed that a single transportation mode operates in each network; therefore, $m$ denotes also the transportation mode. Links are directed, thus $l_{m}^{(s e)} \neq l_{m}^{(e s)}$. A route $q$ is defined as an ordered list of links such that, for each pair of consecutive links in the sequence, $l_{m}^{(s e)}$ and $l_{m^{\prime}}^{\left(s^{\prime} e^{\prime}\right)}$, it holds that $e=s^{\prime}$. A route is unimodal when all its links $l_{m}^{(s e)}$ belong to the same network $m$. In this case, the route is completed with the single transportation mode operating in that network (see above). Similarly, a route is multimodal when its link sequence contains at least two links $l_{m}^{(s e)}$ and $l_{m^{\prime}}^{\left(s^{\prime} e^{\prime}\right)}$ for which it holds that $m \neq m^{\prime}$. Thus, choosing a multimodal route implies at least one change of transportation mode. From the above it follows that mode choice is fully incorporated within the choice of route.

A route cannot reach the same node twice, i.e. cyclical paths that contain at least two links, $l_{m}^{(s e)}$ and $l_{m^{\prime}}^{\left(s^{\prime} e^{\prime}\right)}$, for which any of the statements $s=s^{\prime}, s=e^{\prime}, e=s^{\prime}, e=e^{\prime}$ is true are excluded. For each $O D$ pair $\mathrm{a}_{i j}$ in $\mathcal{C}_{O D}$ there is a set of corresponding possible routes, which is denoted by $\mathcal{Q}\left(\mathrm{a}_{i j}\right)$. It is straightforward that, if origin zone, $i$, and destination zone, $j$, are neighboring, then it holds that any

\footnotetext{
${ }^{6}$ The paper deals explicitly with discrete space. For a continuous-space model with mixed land-use, the interested reader is referred to the well-known contribution by Lucas and Rossi-Hansberg (2002). Continuous space in this paper's setting would introduce additional sensitivity and computational burden without providing further insights.
} 
$l_{m}^{(i j)} \in \mathcal{Q}\left(\mathrm{a}_{i j}\right)$. An alternative, $\mathbf{a}$, is a set that contains the $O D$ pair $\mathrm{a}_{i j}$ and a route $q \in \mathcal{Q}\left(\mathrm{a}_{i j}\right)$, i.e. $\mathbf{a}=\left\{\mathrm{a}_{i j}, q\right\}=\{i, j, q\}$. The choice set, denoted by $\mathcal{C}$, contains all possible alternatives.

\subsection{Households}

The model considers a set of $N$ seemingly identical, but horizontally heterogeneous households (see below), indexed by $n$. Each of these households may locate in any zone $i$, supply labor in any zone $j$ and use any unimodal or multimodal commuting route $q$, as these were defined in Section 2.1. Conditionally on the choice of an alternative, i.e. $\mathbf{a}=\left\{\mathrm{a}_{i j}, q\right\}=\{i, j, q\}$, household $n$ maximizes the utility function:

$$
U_{n \mathbf{a}}=u\left(y_{n \mathbf{a}}, T_{F n \mathbf{a}}\right)+\varepsilon_{n \mathbf{a}},
$$

where $u\left(y_{\mathbf{a}}, T_{F \mathbf{a}}\right)$ is the deterministic portion of utility derived from the consumption of a composite good, $y_{n \mathbf{a}}$, and leisure time, $T_{F n \mathbf{a}} ; \varepsilon_{n \mathbf{a}}$ is a random idiosyncratic term that varies across households and alternatives but does not enter the deterministic portion of utility. Thus, households value differently a series of unobserved factors that vary across different alternatives in the choice set $\mathcal{C}$, but their behavior is identical once a specific alternative $\mathbf{a}$ has been selected. That is, all households that choose alternative $\mathbf{a}$ will face identical budget and time constraints. Consequently, due to function $u(\cdot)$ being identical across households, the latter will choose identical levels of consumption and leisure time, i.e.:

$$
y_{\mathbf{a}}=y_{n \mathbf{a}} \text { and } T_{F n \mathbf{a}}=T_{F \mathbf{a}} .
$$

In line with Anas (2012) the above is referred to as horizontal heterogeneity of seemingly identical households, to distinguish it from any type of vertical heterogeneity that may result in a violation of the conditions stated in (2).

The conditional to alternative $\mathbf{a}=\{i, j, q\}$ budget constraint is:

$$
p y_{\mathbf{a}}=\left(w_{\mathbf{a}}\left(1-\tau_{L}\right)-\tau_{R \mathbf{a}}\right) D_{W \mathbf{a}}+B
$$

where $p$ is the price of a composite consumption good, hereafter normalized to one; $w_{\mathbf{a}}$ is the gross labor remuneration per working day in zone $j ; \tau_{R \mathbf{a}}$ is the pecuniary cost incurred for each commuting trip using route $q ; \tau_{L}$ is the tax rate imposed per unit of labor supply (working day); $D_{W \mathbf{a}}$ is the number of working days under the choice of alternative $\mathbf{a} ; B$ is a horizontal lump-sum transfer from the government to the each household.

The corresponding time constraint is:

$$
T=\left(\overline{t_{L}}+t_{\mathbf{a}}\right) D_{W \mathbf{a}}+T_{F \mathbf{a}}
$$

where $\overline{t_{L}}$ is the duration of the working day, which is assumed to be fixed; $t_{\mathbf{a}}$ is the travel time needed to traverse (two ways) the commuting route $q$ embodied in alternative $\mathbf{a} ; T$ is the total time endowment. Constraints in (3) and (4) can be combined in a single full time constraint, i.e.: 


$$
y_{\mathbf{a}}+\underbrace{\left(\frac{w_{\mathbf{a}}\left(1-\tau_{L}\right)-\tau_{R \mathbf{a}}}{\overline{t_{L}}+t_{\mathbf{a}}}\right)}_{v_{\mathbf{a}}} T_{F \mathbf{a}}-\underbrace{\left(\frac{w_{\mathbf{a}}\left(1-\tau_{L}\right)-\tau_{R \mathbf{a}}}{\overline{t_{L}}+t_{\mathbf{a}}}\right)}_{v_{\mathbf{a}}} T-B=0,
$$

where $v_{\mathbf{a}}$ is the shadow value of time under the choice of alternative a. Equation (5) states that part of the household's full income, i.e. the disposable income if leisure time is set to zero, can be used to buy back some leisure at its shadow value, given by $v_{\mathbf{a}}$. The Lagrangian is:

$$
\mathcal{L}=u\left(y_{\mathbf{a}}, T_{F \mathbf{a}}\right)+\varepsilon_{n \mathbf{a}}-\lambda_{\mathbf{a}}\left[y_{\mathbf{a}}+\left(\frac{w_{\mathbf{a}}\left(1-\tau_{L}\right)-\tau_{R \mathbf{a}}}{\overline{t_{L}}+t_{\mathbf{a}}}\right) T_{F \mathbf{a}}-\left(\frac{w_{\mathbf{a}}\left(1-\tau_{L}\right)-\tau_{R \mathbf{a}}}{\overline{t_{L}}+t_{\mathbf{a}}}\right) T-B\right] .
$$

Differentiating with respect to $y_{\mathbf{a}}$ and $T_{F \mathbf{a}}$ yields:

$$
\begin{gathered}
\frac{\partial u\left(y_{\mathbf{a}}, T_{F \mathbf{a}}\right)}{\partial y_{\mathbf{a}}}=\lambda_{\mathbf{a}} \\
\frac{\partial u\left(y_{\mathbf{a}}, T_{F \mathbf{a}}\right)}{\partial T_{F \mathbf{a}}}=\lambda_{\mathbf{a}} v_{\mathbf{a}} .
\end{gathered}
$$

Because they face identical constraints and the observed part of the preferences is identical, the $N$ seemingly identical households will allocate their budgets and time identically for any given alternative $\mathbf{a}$. The optimal consumption and leisure time are denoted by $y_{\mathbf{a}}=y\left(w_{\mathbf{a}}, \tau_{L}, \tau_{R \mathbf{a}}, B, t_{\mathbf{a}}\right)$ and $T_{F \mathbf{a}}=$ $T_{F}\left(w_{\mathbf{a}}, \tau_{L}, \tau_{R \mathbf{a}}, B, t_{\mathbf{a}}\right)$ respectively. Furthermore, all households will derive the same deterministic utility $V\left(w_{\mathbf{a}}, \tau_{L}, \tau_{R \mathbf{a}}, B, t_{\mathbf{a}}\right)$ from alternative $\mathbf{a}$. However, households may select different alternatives since the random term $\varepsilon_{n \mathbf{a}}$ varies both across alternatives and households. The probability that a randomly selected household chooses alternative $\mathbf{a}$ is denoted by $P_{\mathbf{a}}$.

\subsection{Government}

A benevolent government maximizes the social welfare function:

$$
W\left(V_{\mathbf{0}}\left(w_{\mathbf{0}}, \tau_{L}, \tau_{R \mathbf{0}}, B, t_{\mathbf{0}}\right), \ldots \ldots, V_{\mathbf{k}}\left(w_{\mathbf{k}}, \tau_{L}, \tau_{R \mathbf{k}}, B, t_{\mathbf{k}}\right)\right)
$$

while running a balanced budget, thus:

$$
N(\underbrace{\tau_{L}\left(P_{\mathbf{a}} D_{W \mathbf{a}} W_{\mathbf{a}}\right)}_{\begin{array}{c}
\text { expected labor tax } \\
\text { revenue per capita }
\end{array}}+\underbrace{\sum_{\mathbf{a}}\left(P_{\mathbf{a}} D_{W \mathbf{a}} \tau_{R \mathbf{a}}\right)}_{\begin{array}{c}
\text { expected road toll } \\
\text { revenue per capita }
\end{array}})=N B .
$$




\subsection{Firms}

Labor demand is assumed to be perfectly elastic. That is, equilibrium level of labor is determined by household decisions alone with wages being determined exogenously (i.e. entirely at the national or international level). Therefore, any wage differentials within the region are automatically attributed to the unobserved locational (dis)advantages and the heterogeneity of firms found in different locations. ${ }^{7}$

\subsection{Revenue-neutral swap between a road link charge and the labor tax}

Consider a marginal adjustment of the toll $\tau_{R x}$ charged on link $x$ of the network. Assuming that the total government revenue remains the same, i.e. that $\mathrm{d} B / \mathrm{d} \tau_{R x}=0$, the following auxiliary relationships can be derived:

$$
\begin{aligned}
& \frac{\mathrm{d} y_{\mathbf{a}}}{\mathrm{d} \tau_{R x}}=\underbrace{\frac{\partial y_{\mathbf{a}}}{\partial \tau_{R x}}+\frac{\partial y_{\mathbf{a}}}{\partial t_{\mathbf{a}}} \frac{\mathrm{d} t_{\mathbf{a}}}{\mathrm{d} \tau_{R x}}}_{\tilde{y}_{\mathbf{a} x}}+\frac{\partial y_{\mathbf{a}}}{\partial \tau_{L}} \frac{\mathrm{d} \tau_{L}}{\mathrm{~d} \tau_{R x}}=\tilde{y}_{\mathbf{a} x}+\frac{\partial y_{\mathbf{a}}}{\partial \tau_{L}} \frac{\mathrm{d} \tau_{L}}{\mathrm{~d} \tau_{R x}}, \\
& \frac{\mathrm{d} T_{F \mathbf{a}}}{\mathrm{d} \tau_{R x}}=\underbrace{\frac{\partial T_{F \mathbf{a}}}{\partial \tau_{R x}}+\frac{\partial T_{F \mathbf{a}}}{\partial t_{\mathbf{a}}} \frac{\mathrm{d} t_{\mathbf{a}}}{\mathrm{d} \tau_{R x}}}_{\widetilde{F}_{\mathbf{a} x}}+\frac{\partial T_{F \mathbf{a}}}{\partial \tau_{L}} \frac{\mathrm{d} \tau_{L}}{\mathrm{~d} \tau_{R x}}=\tilde{F}_{\mathbf{a} x}+\frac{\partial T_{F \mathbf{a}}}{\partial \tau_{L}} \frac{\mathrm{d} \tau_{L}}{\mathrm{~d} \tau_{R x}} . \\
& \frac{\mathrm{d} D_{W \mathbf{a}}}{\mathrm{d} \tau_{R x}}=\underbrace{\frac{\partial D_{W \mathbf{a}}}{\partial \tau_{R x}}+\frac{\partial D_{W \mathbf{a}}}{\partial t_{\mathbf{a}}} \frac{\mathrm{d} t_{\mathbf{a}}}{\mathrm{d} \tau_{R x}}}_{\tilde{L}_{\mathbf{a} x}}+\frac{\partial D_{W \mathbf{a}}}{\partial \tau_{L}} \frac{\mathrm{d} \tau_{L}}{\mathrm{~d} \tau_{R x}}=\widetilde{L}_{\mathbf{a} x}+\frac{\partial D_{W \mathbf{a}}}{\partial \tau_{L}} \frac{\mathrm{d} \tau_{L}}{\mathrm{~d} \tau_{R x}} . \\
& \frac{\mathrm{d} V_{\mathbf{a}}}{\mathrm{d} \tau_{R x}}=\underbrace{\frac{\partial V_{\mathbf{a}}}{\partial \tau_{R x}}+\frac{\partial V_{\mathbf{a}}}{\partial t_{\mathbf{a}}} \frac{\mathrm{d} t_{\mathbf{a}}}{\mathrm{d} \tau_{R x}}}_{\widetilde{V}_{\mathbf{a} x}}+\frac{\partial V_{\mathbf{a}}}{\partial \tau_{L}} \frac{\mathrm{d} \tau_{L}}{\mathrm{~d} \tau_{R x}}=\tilde{V}_{\mathbf{a} x}+\frac{\partial V_{\mathbf{a}}}{\partial \tau_{L}} \frac{\mathrm{d} \tau_{L}}{\mathrm{~d} \tau_{R x}} . \\
& \frac{\mathrm{d} P_{\mathbf{a}}}{\mathrm{d} \tau_{R x}}=\sum_{\mathbf{b}} \frac{\partial P_{\mathbf{a}}}{\partial V_{\mathbf{b}}} \cdot \frac{\mathrm{d} V_{\mathbf{b}}}{\mathrm{d} \tau_{R x}}=\sum_{\mathbf{b}} \frac{\partial P_{\mathbf{a}}}{\partial V_{\mathbf{b}}} \cdot \tilde{V}_{\mathbf{b} x}+\frac{\mathrm{d} \tau_{L}}{\mathrm{~d} \tau_{R x}} \cdot \sum_{\mathbf{b}} \frac{\partial P_{\mathbf{a}}}{\partial V_{\mathbf{b}}} \cdot \frac{\partial V_{\mathbf{b}}}{\partial \tau_{L}} .
\end{aligned}
$$

In equations (11)-(14), the auxiliary variables $\tilde{y}_{\mathbf{a} x}, \tilde{F}_{\mathbf{a} x}, \tilde{L}_{\mathbf{a} x}$ and $\tilde{V}_{\mathbf{a} x}$ denote the part of the total (general equilibrium) adjustment in the endogenous variables $y_{\mathbf{a}}\left(w_{\mathbf{a}}, \tau_{L}, \tau_{R \mathbf{a}}, B, t_{\mathbf{a}}\right), T_{F \mathbf{a}}\left(w_{\mathbf{a}}, \tau_{L}, \tau_{R \mathbf{a}}, B, t_{\mathbf{a}}\right)$, $D_{W \mathbf{a}}\left(w_{\mathbf{a}}, \tau_{L}, \tau_{R \mathbf{a}}, B, t_{\mathbf{a}}\right)$ and $V_{\mathbf{a}}\left(w_{\mathbf{a}}, \tau_{L}, \tau_{R \mathbf{a}}, B, t_{\mathbf{a}}\right)$ that occurs due to the adjustment of the pecuniary commuting cost, $\tau_{R \mathbf{a}}$, and commuting time, $t_{\mathbf{a}}$, but not through the adjustment of the labor income tax rate, $\tau_{L}$, which is also endogenous. Similarly, equation (15) decomposes the total change in the choice probability of alternative a that takes place through the adjustment of $\tau_{R \mathbf{a}}$ and $t_{\mathbf{a}}$ versus $\tau_{L}$.

Furthermore, the link-specific road tax base in link $x$ is:

\footnotetext{
${ }^{7}$ For instance, by assuming that the representative firm in location $j$ produces a local intermediate with constant returns to scale technology, using exclusively human labor $\left(y_{j}=A_{j} L_{j}\right)$ it follows from cost minimization and the zero profit assumption that $p=1=\left(\frac{w_{j}}{A_{j}}\right) \Leftrightarrow w_{j}=A_{j}$.
} 


$$
\omega_{1 A x}=\sum_{\mathbf{a}} P_{\mathbf{a}} D_{W \mathbf{a}} I_{q x}
$$

where $I_{r x}$ is an indicator function that equals one if route $q$ embodied in alternative $\mathbf{a}=\{i, j, q\}$ uses road link $x$ and zero otherwise. The total change in the labor and road tax revenue that occurs through the general equilibrium adjustment of all endogenous variables apart from the labor income tax rate, $\tau_{L}$, is:

$$
\omega_{1 B x}=\tau_{L} \sum_{\mathbf{a}}\left(P_{\mathbf{a}} \tilde{L}_{\mathbf{a} x}+D_{W \mathbf{a}}\left(\sum_{\mathbf{b}} \frac{\partial P_{\mathbf{a}}}{\partial V_{\mathbf{b}}} \tilde{V}_{\mathbf{b} x}\right)\right),
$$

and

$$
\omega_{1 C x}=\sum_{\mathbf{a}}\left(\tau_{R \mathbf{a}}\left(P_{\mathbf{a}} \tilde{L}_{\mathbf{a} x}+D_{W \mathbf{a}}\left(\sum_{\mathbf{b}} \frac{\partial P_{\mathbf{a}}}{\partial V_{\mathbf{b}}} \tilde{V}_{\mathbf{b} x}\right)\right)\right),
$$

respectively. Finally, the marginal external congestion cost from an additional trip using a road link $l$ is given by:

$$
\operatorname{mecc}_{l}=t_{l}^{\prime} \cdot \underbrace{\left(\sum_{\mathbf{a}} P_{\mathbf{a}} v_{\mathbf{a}} D_{W \mathbf{a}} I_{q l}\right)}_{\begin{array}{c}
\text { total value of time } \\
\text { in road link } l
\end{array}}
$$

Now, consider the following assumptions:

Assumption A.1. Labor demand is perfectly elastic, i.e. wages are determined exogenously and equilibrium labor is determined entirely from the supply side. It therefore holds that $\mathrm{d} w_{\mathbf{a}} / \mathrm{d} \tau_{R x}=0$.

Assumption A.2. The marginal utility of income is constant across alternatives, i.e. $\lambda_{\mathbf{a}}=\lambda$ for each alternative $\mathbf{a}$ in the choice set.

Assumption A.3. The social welfare function, $W$, is such that:

$$
\frac{\mathrm{d} W}{\mathrm{~d} \tau_{R x}}=N \sum_{\mathbf{a}} P_{\mathbf{a}} \frac{\mathrm{d} V_{\mathbf{a}}}{\mathrm{d} \tau_{R x}}
$$

Assumption A.4. The marginal excess burden of the distortionary labor tax is given by:

$$
M_{L}=-\frac{\sum_{\mathbf{a}}\left(\tau_{L} W_{\mathbf{a}}+\tau_{R \mathbf{a}}\right)\left(P_{\mathbf{a}} \frac{\partial D_{W \mathbf{a}}}{\partial \tau_{L}}+D_{W \mathbf{a}} \cdot\left(\sum_{\mathbf{b}} \frac{\partial P_{\mathbf{a}}}{\partial V_{\mathbf{b}}} \cdot \frac{\partial V_{\mathbf{b}}}{\partial \tau_{L}}\right)\right)}{\sum_{\mathbf{a}} P_{\mathbf{a}} D_{W \mathbf{a}} W_{\mathbf{a}}+\sum_{\mathbf{a}}\left(\tau_{L} W_{\mathbf{a}}+\tau_{R \mathbf{a}}\right)\left(P_{\mathbf{a}} \frac{\partial D_{W \mathbf{a}}}{\partial \tau_{L}}+D_{W \mathbf{a}} \cdot\left(\sum_{\mathbf{b}} \frac{\partial P_{\mathbf{a}}}{\partial V_{\mathbf{b}}} \cdot \frac{\partial V_{\mathbf{b}}}{\partial \tau_{L}}\right)\right)} .
$$

Assumption A.5. All revenue from the corrective tax, $\tau_{R x}$, is used to finance a cut in the distortionary tax $\tau_{L}$. That is: $\mathrm{d} B / \mathrm{d} \tau_{R x}=0$ and $\mathrm{d} \tau_{L} / \mathrm{d} \tau_{R x} \neq 0$. 
With the above established, the following proposition can be made:

Proposition. Under Assumptions A.1-A.5, it holds that:

$$
\frac{1}{\lambda} \frac{\mathrm{d} W}{\mathrm{~d} \tau_{R x}}=N\left(\varepsilon_{P}+\varepsilon_{T I}+\varepsilon_{R R}\right)
$$

where the separate components in (21) are:

$$
\begin{aligned}
& \mathcal{E}_{P x}=\underbrace{\sum_{\mathbf{a}} I_{q x} \Xi_{\mathbf{a} x}\left(\tau_{R x}-m e c c_{x}\right)}_{\text {Aggregate Pigouvian effect }}+\sum_{l \neq x} \underbrace{\sum_{\mathbf{a}} I_{q l} \Xi_{\mathbf{a} x}\left(\tau_{R l}-m e c c_{l}\right)}_{\varepsilon_{P x x}(\mathrm{own})}, \\
& \mathcal{E}_{T I x}=\underbrace{\tau_{L}\left(\sum_{\mathbf{a}} w_{\mathbf{a}} \Xi_{\mathbf{a} x}\right)\left(1+M_{L}\right)}_{\text {tax interaction effect }}, \\
& \mathcal{E}_{R R x}=\underbrace{\left(\sum_{\mathbf{a}} P_{\mathbf{a}} D_{W \mathbf{a}} I_{q x}+\sum_{\mathbf{a}} \tau_{R \mathbf{a}} \Xi_{\mathbf{a} x}\right) M_{L}}_{\text {revenue recycling effect }},
\end{aligned}
$$

where:

$$
\Xi_{\mathbf{a} x}=\left(P_{\mathbf{a}} \tilde{L}_{\mathbf{a} x}+D_{W \mathbf{a}}\left(\sum_{\mathbf{b}} \frac{\partial P_{\mathbf{a}}}{\partial V_{\mathbf{b}}} \cdot \tilde{V}_{\mathbf{b} x}\right)\right) .
$$

Proof. Total differentiation of the budget constraint in (5) w.r.t. $\tau_{R x}$ yields:

$$
\frac{\mathrm{d} y_{\mathbf{a}}}{\mathrm{d} \tau_{R x}}+v_{\mathbf{a}} \frac{\mathrm{d} T_{F \mathbf{a}}}{\mathrm{d} \tau_{R x}}=\left(T_{F \mathbf{a}}-T\right)\left(\frac{\frac{\mathrm{d} \tau_{L}}{\mathrm{~d} \tau_{R x}} w_{\mathbf{a}}+I_{r x}+v_{\mathbf{a}} \frac{\mathrm{d} t_{\mathbf{a}}}{\mathrm{d} \tau_{R x}}}{\overline{t_{L}}+t_{\mathbf{a}}}\right)
$$

Total differentiation of the utility function in (1) w.r.t. $\tau_{R x}$ in combination with (7) and (8) yields:

$$
\frac{1}{\lambda_{\mathbf{a}}} \frac{\mathrm{d} u}{\mathrm{~d} \tau_{R x}}=\left(\frac{\mathrm{d} y_{\mathbf{a}}}{\mathrm{d} \tau_{R x}}+v_{\mathbf{a}} \frac{\mathrm{d} T_{F \mathbf{a}}}{\mathrm{d} \tau_{R x}}\right)
$$

It follows from (26), (27) and (4) that:

$$
\frac{\mathrm{d} u}{\mathrm{~d} \tau_{R x}}=-\lambda_{\mathbf{a}} \cdot D_{W \mathbf{a}} \cdot\left(\frac{\mathrm{d} \tau_{L}}{\mathrm{~d} \tau_{R x}} \cdot w_{\mathbf{a}}+I_{r x}+v_{\mathbf{a}} \cdot \frac{\mathrm{d} t_{\mathbf{a}}}{\mathrm{d} \tau_{R x}}\right)
$$


Due to Assumption A.5, total differentiation of the government budget constraint in (10) w.r.t. $\tau_{R x}$ yields:

$$
\frac{\mathrm{d} \tau_{L}}{\mathrm{~d} \tau_{R x}}\left(\sum_{\mathbf{a}} P_{\mathbf{a}} D_{W \mathbf{a}} W_{\mathbf{a}}\right)+\tau_{L} \sum_{\mathbf{a}} w_{\mathbf{a}} \frac{\mathrm{d}\left(P_{\mathbf{a}} D_{W \mathbf{a}}\right)}{\mathrm{d} \tau_{R x}}+\left(\sum_{\mathbf{a}} P_{\mathbf{a}} D_{W \mathbf{a}} I_{q x}\right)+\sum_{\mathbf{a}} \tau_{R \mathbf{a}} \cdot \frac{\mathrm{d}\left(P_{\mathbf{a}} D_{W \mathbf{a}}\right)}{\mathrm{d} \tau_{R x}}=0 .
$$

The total change in in working days supplied through the choice of an arbitrary alternative $\mathbf{a}$ is:

$$
\frac{\mathrm{d}\left(P_{\mathbf{a}} D_{W \mathbf{a}}\right)}{\mathrm{d} \tau_{R x}}=\underbrace{P_{\mathbf{a}} \tilde{L}_{\mathbf{a} x}+D_{W \mathbf{a}}\left(\sum_{\mathbf{b}} \frac{\partial P_{\mathbf{a}}}{\partial V_{\mathbf{b}}} \cdot \tilde{V}_{\mathbf{b} x}\right)}_{\Xi_{\mathbf{a} x}}+\frac{\mathrm{d} \tau_{L}}{\mathrm{~d} \tau_{R x}} \underbrace{\left(P_{\mathbf{a}} \frac{\partial D_{W \mathbf{a}}}{\partial \tau_{L}}+D_{W \mathbf{a}}\left(\sum_{\mathbf{b}} \frac{\partial P_{\mathbf{a}}}{\partial V_{\mathbf{b}}} \cdot \frac{\partial V_{\mathbf{b}}}{\partial \tau_{L}}\right)\right)}_{\Xi_{\mathbf{a}}^{L}} .
$$

where $\Xi_{\mathbf{a} x}$ is given in (23) and:

$$
\Xi_{\mathbf{a}}^{L}=\left(P_{\mathbf{a}} \frac{\partial D_{W \mathbf{a}}}{\partial \tau_{L}}+D_{W \mathbf{a}}\left(\sum_{\mathbf{b}} \frac{\partial P_{\mathbf{a}}}{\partial V_{\mathbf{b}}} \cdot \frac{\partial V_{\mathbf{b}}}{\partial \tau_{L}}\right)\right)
$$

The term $\Xi_{\mathbf{a} x}$ expresses the induced change in expected labor supplied conditional on the choice of alternative $\mathbf{a}=\{i, j, q\}$ that is directed entirely through the adjustments of all endogenous variables except for labor supply. That is, the first component of the right hand side in (23) is the change in the number of working days occurring because the adjustment in road toll $\tau_{R x}$ will cause a change in commuting time and may affect the commuting cost associated with alternative $\mathbf{a}$; the second component in (23) encapsulates the adjustment in labor supply occurring because the change in commuting times and costs will affect the relative attractiveness of alternative $\mathbf{a}$, i.e. $P_{\mathbf{a}}$.

Similarly, the term $\Xi_{\text {a }}^{L}$ filters the induced change in expected labor supplied conditional on the choice of alternative $\mathbf{a}=\{i, j, q\}$ that stems exclusively from the adjustment of the tax on labor income. That change can be decomposed in two parts: (i) an adjustment occurring because the change in $\tau_{L}$ affects the (conditional on a) shadow value of leisure time, and (ii) a change occurring from the horizontal adjustment of $\tau_{L}$, which alters the relative attractiveness of all alternatives, and thus perturbs $P_{\mathbf{a}}$. Using (30), the second and fourth component of (29) can be developed further. That is:

$$
\tau_{L} \sum_{\mathbf{a}} w_{\mathbf{a}} \frac{\mathrm{d}\left(P_{\mathbf{a}} D_{W \mathbf{a}}\right)}{\mathrm{d} \tau_{R x}}=\frac{\mathrm{d} \tau_{L}}{\mathrm{~d} \tau_{R x}}\left(\sum_{\mathbf{a}} \tau_{L} w_{\mathbf{a}} \Xi_{\mathbf{a}}^{L}\right)+\sum_{\mathbf{a}} \tau_{L} w_{\mathbf{a}} \Xi_{\mathbf{a} x}
$$

and

$$
\sum_{\mathbf{a}} \tau_{R \mathbf{a}} \frac{\mathrm{d}\left(P_{\mathbf{a}} D_{W \mathbf{a}}\right)}{\mathrm{d} \tau_{R x}}=\frac{\mathrm{d} \tau_{L}}{\mathrm{~d} \tau_{R x}}\left(\sum_{\mathbf{a}} \tau_{R \mathbf{a}} \Xi_{\mathbf{a}}^{L}\right)+\sum_{\mathbf{a}} \tau_{R \mathbf{a}} \Xi_{\mathbf{a} x}
$$

Inserting (32) and (33) into (29) and rearranging yields:

Second-best road taxes in polycentric networks with distorted labor markets 


$$
\frac{\mathrm{d} \tau_{L}}{\mathrm{~d} \tau_{R x}}=\frac{-\left(\sum_{\mathbf{a}} P_{\mathbf{a}} D_{W \mathbf{a}} I_{r x}\right)-\sum_{\mathbf{a}}\left(\left(w_{\mathbf{a}} \tau_{L}+\tau_{R \mathbf{a}}\right) \cdot \Xi_{\mathbf{a} x}\right)}{\left(\sum_{\mathbf{a}} P_{\mathbf{a}} D_{W \mathbf{a}} w_{\mathbf{a}}\right)+\sum_{\mathbf{a}}\left(\left(w_{\mathbf{a}} \tau_{L}+\tau_{R \mathbf{a}}\right) \cdot \Xi_{\mathbf{a}}^{L}\right)} .
$$

Using the auxiliary term $\Xi_{\mathbf{a}}^{L}$, the marginal excess burden in (20) can now be rewritten as:

$$
M_{L}=-\frac{\sum_{\mathbf{a}}\left(\tau_{L} w_{\mathbf{a}}+\tau_{R \mathbf{a}}\right) \Xi_{\mathbf{a}}^{L}}{\sum_{\mathbf{a}} P_{\mathbf{a}} D_{W \mathbf{a}} W_{\mathbf{a}}+\sum_{\mathbf{a}}\left(\tau_{L} w_{\mathbf{a}}+\tau_{R \mathbf{a}}\right) \Xi_{\mathbf{a}}^{L}} .
$$

Now, from (34) and (35) it follows that:

$$
\frac{\mathrm{d} \tau_{L}}{\mathrm{~d} \tau_{R x}}=M_{L} \frac{\sum_{\mathbf{a}} P_{\mathbf{a}} D_{W \mathbf{a}} I_{r x}+\sum_{\mathbf{a}}\left(\left(w_{\mathbf{a}} \tau_{L}+\tau_{R \mathbf{a}}\right) \Xi_{\mathbf{a x}}\right)}{\sum_{\mathbf{a}}\left(\tau_{L} w_{\mathbf{a}}+\tau_{R \mathbf{a}}\right) \Xi_{\mathbf{a}}^{L}} .
$$

Using (28) in conjunction to Assumption A.3 yields:

$$
\frac{\mathrm{d} W}{\mathrm{~d} \tau_{R x}}=-N\left(\left(\frac{\mathrm{d} \tau_{L}}{\mathrm{~d} \tau_{R x}} \sum_{\mathbf{a}} P_{\mathbf{a}} \lambda_{\mathbf{a}} D_{W \mathbf{a}} W_{\mathbf{a}}\right)+\sum_{\mathbf{a}} P_{\mathbf{a}} \lambda_{\mathbf{a}} D_{W \mathbf{a}} I_{q x}+\sum_{\mathbf{a}} P_{\mathbf{a}} \lambda_{\mathbf{a}} v_{\mathbf{a}} D_{W \mathbf{a}} \frac{\mathrm{d} t_{\mathbf{a}}}{\mathrm{d} \tau_{R x}}\right) .
$$

Using Assumption A.4 on the constant marginal utility of income across alternatives, i.e. $\lambda_{\mathbf{a}}=\lambda$, (37) becomes:

$$
\frac{1}{\lambda} \frac{\mathrm{d} W}{\mathrm{~d} \tau_{R x}}=-N(\underbrace{\left(\frac{\mathrm{d} \tau_{L}}{\mathrm{~d} \tau_{R x}} \sum_{\mathbf{a}} P_{\mathbf{a}} D_{W \mathbf{a}} W_{\mathbf{a}}\right)+\sum_{\mathbf{a}} P_{\mathbf{a}} D_{W \mathbf{a}} I_{q x}}_{\mathcal{D}}+\underbrace{\sum_{\mathbf{a}} P_{\mathbf{a}} v_{\mathbf{a}} D_{W \mathbf{a}} \frac{\mathrm{d} t_{\mathbf{a}}}{\mathrm{d} \tau_{R x}}}_{\mathcal{P}}) .
$$

With further algebraic manipulations, it is shown (see intermediate steps A and $\mathbf{B}$ in Appendix D) that expression $\mathcal{D}$ in (38) is equal to:

$$
\mathcal{D}=-\underbrace{\left(\sum_{\mathbf{a}} P_{\mathbf{a}} D_{W \mathbf{a}} I_{q x}+\sum_{\mathbf{a}}\left(\tau_{R \mathbf{a}} \Xi_{\mathbf{a x}}\right)\right) M_{L}}_{\mathcal{E}_{R R}}-\underbrace{\tau_{L}\left(\sum_{\mathbf{a}} w_{\mathbf{a}} \Xi_{\mathbf{a} x}\right)\left(1+M_{L}\right)}_{\varepsilon_{T I}}-\underbrace{\sum_{\mathbf{a}}\left(\tau_{R \mathbf{a}} \Xi_{\mathbf{a} x}\right)}_{\omega_{1 C x}} .
$$

It is also shown (intermediate step $\mathbf{C}$ in Appendix D) that expression $\mathcal{P}$ in (38) is equal to:

$$
\mathcal{P}=\underbrace{\sum_{\mathbf{a}}\left(\tau_{R \mathbf{a}} \Xi_{\mathbf{a} x}\right)}_{-\omega_{1 C x}}-\underbrace{\sum_{\mathbf{a}} I_{q x} \Xi_{\mathbf{a} x}\left(\tau_{R x}-\operatorname{mecc}_{x}\right)+\sum_{l \neq x} \sum_{\mathbf{a}} I_{q l} \Xi_{\mathbf{a} x}\left(\tau_{R l}-\operatorname{mecc}_{l}\right)}_{\mathcal{E}_{P}} .
$$

Finally, combining (38), (39) and (40) yields:

Second-best road taxes in polycentric networks with distorted labor markets 


$$
-N(\mathcal{D}+\mathcal{P})=\frac{1}{\lambda} \frac{\mathrm{d} W}{\mathrm{~d} \tau_{R x}}=N\left(\varepsilon_{P x}+\varepsilon_{T I x}+\varepsilon_{R R x}\right)
$$

(Q.E.D.)

\subsection{Discussion}

\subsubsection{Marginal effects of a revenue-neutral tax swap in a network}

Section 2.5 provided an analytic formula for the welfare effect induced by a marginal, revenue-neutral swap between the corrective tax on an arbitrary road link $\left(\tau_{R x}\right)$ and the distortionary tax on labor income $\left(\tau_{L}\right)$. That welfare effect is decomposed into four separate effects.

First, welfare is affected through an own-Pigouvian effect $\left(\mathcal{E}_{P x x}\right)$. Since increasing the corrective $\operatorname{tax}\left(\tau_{R x}\right)$ reduces traffic in that link, from (22) it follows that the above effect is positive whenever $\tau_{R x}$ lies below its Pigouvian level (mecc $c_{x}$ ) and vice versa. Second, the adjustment of $\tau_{R x}$ induces a series of cross-Pigouvian effects $\left(\mathcal{E}_{P l x}\right)$, one for each road link $l \neq x$. Each of these effects is the change of the deadweight loss occurring in link $l$, due to the adjustment of the corrective tax in link $x$. From (22) it follows that whenever links $l$ and $x$ are general equilibrium substitutes, $\mathcal{E}_{P l x}$ is positive (negative) if the corrective tax on link $l\left(\tau_{R l}\right)$ lies above (below) its Pigouvian level ( $\left.m e c c_{l}\right)$. Similarly, whenever links $l$ and $x$ are general equilibrium complements, $\mathcal{E}_{P l x}$ is positive (negative) if $\tau_{R l}$ lies below (above) $m e c c_{l}$. The sum of the own-Pigouvian effect and the cross-Pigouvian effects is the aggregate Pigouvian effect $\left(\mathcal{E}_{P X}\right)$. This is the welfare change from the adjustment of external effects in the entire network, following the adjustment of $\tau_{R x}$. By tracing the components of (22) through formulae (25), (13) and (14), it becomes apparent that the aforementioned effects are purified from the impact a change in the distortionary $\operatorname{tax}\left(\tau_{L}\right)$ would have on the general equilibrium levels of the external effects. Furthermore, the formula in (22) highlights the role of partial taxation in a double-dividend setting. Under a partial taxation policy, the externality tax $\left(\tau_{R l}\right)$ in one or more network links is fixed to zero. It then follows that increasing $\tau_{R x}$ will generate a negative (positive) cross-Pigouvian effect in every link $l$ that is a general equilibrium substitute (complement) of link $x$, provided that $\tau_{R l}=0$. Furthermore, the magnitude of the cross-Pigouvian effects in the untaxed links depends on the marginal external costs on them.

Apart from the Pigouvian effects, the decomposition formula in (21) contains a tax interaction effect $\left(\mathcal{E}_{T I X}\right)$ and a revenue-recycling effect $\left(\mathcal{E}_{R R x}\right)$. The former effect is the efficiency loss in the labor market caused by a marginal increase in $\tau_{R x}$. That is, the adjustment of $\tau_{R x}$ affects the commuting costs of those using routes that include the link $x$; moreover, it affects, through the overall changes in traffic levels, the commuting times in all routes, independent of whether they incorporate link $x$ or not. This causes an erosion of the labor income tax base (i.e. the sum placed within brackets in (23)). The erosion of the labor income tax base is purified from the impact a change in the distortionary tax $\left(\tau_{L}\right)$ would have on the general equilibrium level of labor supply. Thus, multiplying the tax base erosion with the income tax rate $\left(\tau_{L}\right)$ yields the foregone income tax revenue due to the marginal increase of $\tau_{R x}$. Weighting the foregone revenue with the marginal social cost of raising a monetary unit through the labor income tax, i.e. $\left(1+M_{L}\right)$, yields the tax interaction effect $\left(\mathcal{E}_{T I x}\right)$. Finally, the revenue-recycling effect $\left(\mathcal{E}_{R R x}\right)$ is the welfare change realized in the distorted labor market due to the adjustment of the labor income tax rate. This adjustment is financed by the additional revenue generated in every link of the network, represented by the terms placed within brackets in (24).

Second-best road taxes in polycentric networks with distorted labor markets 
The decomposition formula expressed in (21)-(24) bears a series of policy implications. First, it is often not feasible to compute the Pigouvian effects of an externality tax. If, instead, the tax-interaction and revenue-recycling effects can be approximated, a policy decision may be justified entirely on the existence of the second dividend. That is, if the revenue-recycling effect offsets the tax interaction effect, the introduction of the revenue-neutral tax swap is justified from an efficiency point of view, as long as the aggregate Pigouvian effect of it is non-negative. Second, if the aggregate Pigouvian effect of a corrective tax offsets its negative tax interaction effect, then the introduction of the externality tax is justified even without the presence of the labor tax cut. The importance of this becomes more obvious when the various technical obstacles in the implementation of a revenue-neutral tax swap are taken into account. ${ }^{8}$ Finally, when the system has been optimized from an environmental point of view the comparison of (23) and (24) will detect the corrective taxes whose value should be set above or below the Pigouvian levels of the corresponding externalities.

\subsubsection{Income effects}

Earlier contributions in literature have provided analytic decompositions in simpler settings with a single distortionary tax and a single externality (e.g. Goulder et al., 1999). To some extent, the exposition in Section 2.5 generalizes the theory of double dividend in a probabilistic setting with unobserved household heterogeneity and multiple interdependent externalities. A series of insights can be derived from that that exercise.

First, the decomposition assumes that income effects are off, i.e. the marginal utility of income should not only be constant across any pair of households $\left(n, n^{\prime}\right)$ that end up selecting the same alternative $\mathbf{a}$ (that is, $\lambda_{\mathbf{a} n}=\lambda_{\mathbf{a} n^{\prime}}=\lambda_{\mathbf{a}}$ ); in order to reach the decomposition in (41), $\lambda$ should also be equalized across the choice set of any arbitrary household, i.e. for every pair of alternatives $\left(\mathbf{a}, \mathbf{a}^{\prime}\right)$ it should hold that: $\lambda_{\mathbf{a} n}=\lambda_{\mathbf{a}^{\prime} n}=\lambda$. When the latter condition is violated the right hand side of (41) will contain an additional term, $\mathcal{E}_{D x}$, which functions as a redistribution effect. That is:

$$
\left\{\begin{aligned}
\frac{1}{\bar{\lambda}} \frac{\mathrm{d} W}{\mathrm{~d} \tau_{R x}} & =N\left(\mathcal{E}_{P x}+\mathcal{E}_{T I x}+\varepsilon_{R R x}\right)+\varepsilon_{D x} \\
\mathcal{E}_{D x} & =-N \sum_{\mathbf{a}} P_{\mathbf{a}} \tilde{\lambda}_{\mathbf{a}} D_{W \mathbf{a}}\left(\frac{\mathrm{d} \tau_{L}}{\mathrm{~d} \tau_{R x}} w_{\mathbf{a}}+I_{q x}+v_{\mathbf{a}} \frac{\mathrm{d} t_{\mathbf{a}}}{\mathrm{d} \tau_{R x}}\right)^{\prime}
\end{aligned}\right.
$$

where $\bar{\lambda}$ denotes an arbitrary (e.g. the average) level of marginal utility of income and $\tilde{\lambda}_{\mathbf{a}}$ the alternativespecific deviation from $\bar{\lambda}$. When marginal utility is equal across alternatives, $\varepsilon_{D x}$ collapses to zero and (42) coincides with (41).

However, with income effects on, social welfare can be increased by adjusting the tax $\tau_{R x}$ in a way that favors the choice of alternatives with relatively high marginal valuation of income. This becomes clearer when the distortionary tax is set to zero (implying $\varepsilon_{T I x}=0$ ), all externality taxes are set to their Pigouvian levels (implying $\mathcal{E}_{P x}=0$ ) and their revenues are returned lump-sum $\left(\varepsilon_{R R x}=0\right)$. Although the above setting appears to be first-best, utility is not maximized unless social benefit from redistribution, i.e. the term $\varepsilon_{D x}$ in (42), is also zero, reflecting this way the anonymity of lump-sum

\footnotetext{
${ }^{8}$ That is, most often the corrective tax and the distortionary tax are controlled by different government authorities and serve different objectives, i.e. the former mitigates external effects while the latter is used to raise revenue.
}

Second-best road taxes in polycentric networks with distorted labor markets 
revenue recycling. ${ }^{9}$ A direct implication of this is that the optimal set of corrective taxes in the network will be such that the marginal externality deadweight loss, caused by the adjustment of any $\tau_{R x}$, will be equal to the marginal distributional benefits from that adjustment.

Therefore, in settings with unobserved horizontal heterogeneity the optimal corrective taxes may differ substantially depending on whether income effects are considered or assumed away. This result extends the insights from Anas (2012) who shows, in a simple setting without network, that social welfare maximization cannot be achieved without alternative-specific redistribution instruments that aim to equalize the marginal utility of income across alternatives. From (42) it follows that if such alternativespecific lump-sum transfers are available and distortionary taxation is absent, efficiency and equity could be achieved with separate policy instruments, i.e. with corrective taxation and cross-alternative lump-sum transfers, although they both contribute to social welfare. The result is also aligned with contributions in second-best corrective taxation under observable heterogeneity. For instance, in Jacobs and de Mooij (2015) a modified corrective tax (that deviates from its Pigouvian level) and individualized transfers are both required to achieve the optimum.

\section{Expanded numerical model}

The model proposed in this section is a network-based, polycentric extension of the general equilibrium monocentric city models by Verhoef (2005), Tikoudis et al. (2015a; 2015b), and is in line with the existing urban general equilibrium models based on discrete-continuous household optimization. These contributions include: Anas and Kim (1996); Anas and Xu (1999); Anas and Liu (2007); Tscharaktschiew and Hirte (2010); Anas and Hiramatsu (2012); Hirte and Tscharaktchiew, (2013); Dröes and Rietveld (2015).

\subsection{Households}

The model assumes the existence of an exogenous population of $N$ seemingly identical households. Without any loss of generality, $N$ is normalized to one. For each feasible alternative, $\mathbf{a}=\left\{\mathrm{a}_{i j}, q\right\}$, household $n$ maximizes the quasi-linear utility function:

$$
U_{n \mathbf{a}}=z_{\mathbf{a}}+\pi_{0} y_{\mathbf{a}}+\pi_{1}(\underbrace{S_{\mathbf{a}}^{\alpha} T_{F \mathbf{a}}^{\beta}}_{x_{\mathbf{a}}})^{\gamma}+\varepsilon_{n \mathbf{a}}
$$

where $\mathrm{z}_{\mathbf{a}}$ is an alternative-specific constant (see below); $y_{\mathbf{a}}$ corresponds to the consumption of a regional composite good (numéraire); $x_{\mathbf{a}}$ is a subutility function of housing consumption, $s_{\mathbf{a}}$, and leisure, $T_{F \mathbf{a}} ; \varepsilon_{n \mathbf{a}}$ is a random term that is i.i.d. extreme value type $I$ across households and alternatives in the choice set $\mathcal{C}$.

\footnotetext{
${ }^{9}$ This finding, which has been first highlighted by Anas (2012) for a stylized setting with two locations, has been confirmed using alternative specifications of a simplified (monocentric serial network) model in which income effects were on. These specifications were used to test the optimality of the Pigouvian toll with horizontal lump-sum recycling in the case where $\tau_{L}=0$, i.e. with congestion as the only failure in the model. In all cases the constrained (due to horizontal revenue recycling) optima were Pareto preferred to the Pigouvian toll.
}

Second-best road taxes in polycentric networks with distorted labor markets 
The marginal utility of income is constant and equal to $\pi_{0} \cdot{ }^{10}$ As in the theoretical model of Section 2 , labor supply is inelastic in the extensive margin, i.e. working days are of fixed duration, $\overline{t_{L}}$, which is normalized to one. The household anticipates every trip to work to require $t_{\mathbf{a}}$ units of time. From (4) it follows that: ${ }^{11}$

$$
D_{\mathrm{Wa}}=\frac{T-T_{F \mathbf{a}}}{1+t_{\mathbf{a}}} .
$$

The net wage per working day is defined as the difference between the after tax wage in zone $j$, that is $w_{\mathbf{a}}\left(1-\tau_{L}\right)$, the expected pecuniary cost of commuting $\left(c_{\mathbf{a}}\right)$ and the toll expenditure $\left(\tau_{R \mathbf{a}}\right)$ under the choice of alternative $\mathbf{a}$. The full income, $M_{\mathbf{a}}$, of the household that has chosen alternative $\mathbf{a}=\{i, j, q\}$ is the maximum income that can be realized when leisure time is zero. That is:

$$
M_{\mathbf{a}}=B+B_{\ell}+\underbrace{\left(\frac{w_{\mathbf{a}}\left(1-\tau_{L}\right)-c_{\mathbf{a}}-\tau_{R \mathbf{a}}}{1+t_{\mathbf{a}}}\right)}_{\text {value of time: } v_{\mathbf{a}}} T,
$$

where $B$ denotes a lump-sum transfer from the government to the household and $B_{\ell}$ is the income from land rents, which is returned to households lump-sum. Both $B$ and $B_{\ell}$ are exogenous to the household and independent of the chosen alternative, a, i.e. revenue recycling is horizontal. For simplicity, it is assumed that intra-zonal travel time and cost is zero (i.e. $c_{\mathbf{a}}=t_{\mathbf{a}}=0$ whenever $\mathbf{a}=\{i, j, q\}$ is such that $i=j$ ). Normalizing the price of the composite regional (see below) numéraire to one, the full time constraint provided in (5) now becomes:

$$
y_{\mathbf{a}}+p_{H i} S_{\mathbf{a}}+v_{\mathbf{a}} T_{F \mathbf{a}}-v_{\mathbf{a}} T-B-B_{\ell}=0,
$$

where $p_{H i}$ the unit price of residential floor space at the zone indexed by $i$. The Lagrangian corresponding to the maximization of (43) subject to (46) and the associated non-negativity constraints is: ${ }^{12}$

$$
\begin{aligned}
\mathcal{L}=\pi_{0} y_{\mathbf{a}}+\pi_{1} & \left(S_{\mathbf{a}}^{\alpha} T_{F \mathbf{a}}^{\beta}\right)^{\gamma}+\varepsilon_{n \mathbf{a}}-\lambda_{\mathbf{a}}\left[v_{\mathbf{a}} T_{F \mathbf{a}}+y_{\mathbf{a}}+p_{H i} S_{\mathbf{a}}-\left(B+B_{\ell}+v_{\mathbf{a}} T\right)\right] \\
& +\vartheta_{C} y_{\mathbf{a}}+\vartheta_{F}^{U}\left(T-T_{F \mathbf{a}}\right) .
\end{aligned}
$$

Solving for an interior optimum yields the Marshallian demand functions for housing and leisure time.

$$
S_{\mathbf{a}}^{*}=\left(\frac{p_{H i} \pi_{0}}{\alpha \gamma \pi_{1}}\right)^{\frac{1}{\gamma-1}}\left(\frac{\alpha v_{\mathrm{a}}}{\beta p_{H i}}\right)^{\frac{\beta \gamma}{\gamma-1}}
$$

\footnotetext{
${ }^{10}$ Given that the parameters of the Cobb-Douglas subutility function are such that $\alpha<1, \beta<1$ and $\alpha+\beta=1$, the marginal utility with respect to the residential space and leisure is diminishing for $\gamma<1$.

${ }^{11}$ By assuming an 8-hour working day and by setting $t_{L}=1.0$, the within-day time is measured in 8-hour intervals. This means that a two-way commuting trip of $t_{\mathrm{a}}=0.15$ time units corresponds to a one-way commuting time of 36 minutes.

${ }^{12}$ By definition, both housing consumption and leisure are essential, thus $S_{\mathrm{a}}>0$ and $T_{\mathrm{Fa}}>0$. Furthermore, leisure is upper-bounded by the total time endowment, therefore $T_{F \mathrm{a}}<T\left(=T\right.$ if $\left.D_{W \mathrm{a}}^{*}=0\right)$, and consumption has to be nonnegative, i.e. $y_{\mathrm{a}} \geq 0$.
} 


$$
T_{F \mathbf{a}}^{*}=\left(\frac{p_{H i} \pi_{0}}{\alpha \gamma \pi_{1}}\right)^{\frac{1}{\gamma-1}}\left(\frac{\alpha v_{\mathrm{a}}}{\beta p_{H i}}\right)^{\frac{\beta \gamma}{\gamma-1}-1} .
$$

Inserting (49) into (44) yields the optimal labor supply for alternative a:

$$
D_{W \mathbf{a}}^{*}=\frac{T-\left(\frac{p_{H i} \pi_{0}}{\alpha \gamma \pi_{1}}\right)^{\frac{1}{\gamma-1}}\left(\frac{\alpha v_{\mathbf{a}}}{\beta p_{H i}}\right)^{\frac{\beta \gamma}{\gamma-1}-1}}{1+t_{\mathbf{a}}} .
$$

Optimal consumption, $y_{\mathbf{a}}^{*}$, can be computed by inserting (48) and (49) into (46). Substituting $y_{\mathbf{a}}^{*}$, $s_{\mathbf{a}}^{*}$ and $T_{F \mathbf{a}}^{*}$ into the objective function and allowing for an alternative-specific constant, $\mathrm{z}_{\mathbf{a}}$, yields the indirect utility of alternative $\mathbf{a}$ :

$$
V_{\mathbf{a}}^{*}\left(w_{j}, p_{H i}, \tau_{L}, c_{\mathbf{a}}, t_{\mathbf{a}}, B, B_{\ell}\right)=\mathrm{z}_{\mathbf{a}}+\Xi+\pi_{0}\left(\mathrm{e}+v_{\mathbf{a}} T\right)+v_{\mathbf{a}}^{\frac{\beta \gamma}{\gamma-1}} p_{H i}^{\frac{\alpha \gamma}{\gamma-1}},
$$

where:

$$
\Xi=\pi_{0}^{\frac{\gamma}{\gamma-1}} \pi_{1}^{\frac{1}{1-\gamma}}\left(\alpha^{-\frac{\alpha \gamma}{\gamma-1}} \beta^{-\frac{\beta \gamma}{\gamma-1}} \gamma^{-\frac{\gamma}{\gamma-1}}-\alpha^{\frac{\alpha \gamma}{\gamma-1}} \beta^{\frac{\beta \gamma}{\gamma-1}} \gamma^{\frac{1}{1-\gamma}}\right)
$$

The alternative-specific constant, $\mathrm{z}_{\mathbf{a}}$, is the sum of: i) a residential-specific constant, $\mathrm{z}_{I i}$, that captures the average utility of locational characteristics (e.g. amenities, ambient pollution) not modeled specifically in zone $i$, ii) an employment-specific constant, $\mathrm{z}_{J j}$, that captures the average unobserved utility from working in zone $j$ (e.g. prospects for a better future job arrangement due to spatial concentration of jobs) and iii) a mode-specific constant, $\mathrm{z}_{M}$, (discussed below). Therefore:

$$
\mathrm{z}_{\mathrm{a}}=\mathrm{z}_{I i}+\mathrm{z}_{J j}+\mathrm{z}_{M}
$$

The mode-specific constant, $\mathrm{z}_{M}$, captures the average (dis)utility of commuting stemming from factors that are not modelled explicitly: waiting times, changing from a private to a public mode and vice versa, in-vehicle comfort, cruising time, etc. More specifically, it is assumed that:

$$
\mathrm{z}_{M}=\sum_{m} I(q, m) \cdot \mathrm{z}_{m}+I_{t}(q) \cdot \mathrm{z}_{t}
$$

where the indicator function $I(q, m)$ equals one if route $q$ makes use of mode $m$ (zero otherwise); the indicator function $I_{t}(q)$ equals one if route $q$ involves a transit from a private to a public mode or vice versa (zero otherwise); $\mathrm{z}_{m}$ is the average disutility inflicted to the individual by the use of mode $m$; and $\mathrm{z}_{t}$ is the average disutility of a mode change. Total utility is, thus:

$$
U_{n \mathbf{a}}^{*}=\mathrm{z}_{\mathbf{a}}+\Xi+\pi_{0}\left(B+B_{\ell}+v_{\mathbf{a}} T\right)+v_{\mathbf{a}}^{\frac{\beta \gamma}{\gamma-1}} p_{H i}^{\frac{\alpha \gamma}{\gamma-1}}+\varepsilon_{n \mathbf{a}} .
$$

The expectation of the maximum utility (hereafter, $\Omega$ ) that can be derived when facing the choice set $\mathcal{C}$ is the well-known logsum expression: 


$$
\Omega=\hat{\lambda}\left[\varepsilon+\log \sum_{\mathbf{a} \in \mathcal{C}} \exp \left(V_{\mathbf{a}}^{*} / \hat{\lambda}\right)\right]
$$

where $\varepsilon \approx 0.5772$ is the Euler constant and $\hat{\lambda}$ the scale parameter of the i.i.d. extreme value type $I$ distribution. The resulting logit choice probability for alternative a by a randomly selected household is:

$$
P_{\mathbf{a}}=\frac{\exp \left(V_{\mathbf{a}}^{*} / \hat{\lambda}\right)}{\sum_{\mathbf{b} \in \mathcal{C}} \exp \left(V_{\mathbf{b}}^{*} / \hat{\lambda}\right)} .
$$

\subsection{Firms}

A competitive, representative firm is located in each zone $j \in \mathcal{J}$ and produces a zone-specific intermediate output, $Q_{j}$, under constant returns to scale, using capital $(K)$, and labor $(L)$ :

$$
Q_{j}^{S}=A_{j} K^{\delta} L^{1-\delta},
$$

where $A_{j}$ denotes the zone-specific total factor productivity. The zero profit condition, implies that the price of the good produced in zone $j, p_{j}$, is equal to the unit cost:

$$
p_{j}=\frac{1}{A_{j}} \underbrace{\left\{\left(\frac{\delta}{1-\delta}\right)^{1-\delta}+\left(\frac{1-\delta}{\delta}\right)^{\delta}\right\}}_{\Phi} R^{\delta} w_{j}^{1-\delta},
$$

where $w_{j}$ is the local equilibrium wage, and $R$ the exogenous price of capital. The conditional factor demands for labor and capital can be computed using the Shephard's lemma, i.e. by differentiating (59) with respect to the corresponding price of the input and multiplying with the level of output, $Q_{j}$. Thus, labor demand is:

$$
L_{j}^{D}=\frac{1}{A_{j}} \Phi(1-\delta) R^{\delta} w_{j}^{-\delta} Q_{j}^{S}
$$

and capital demand is:

$$
K_{j}^{D_{f}}=\frac{1}{A_{j}} \Phi \delta R^{\delta-1} w_{j}^{1-\delta} Q_{j}^{S}
$$

An assembly industry combines the $J$ distinct intermediate goods (which are bought from the local firms, each at price $p_{j}$ ) to produce the composite good demanded by the consumers and by the rest of the world. The amount of the composite good produced is given by the Cobb-Douglas production function:

$$
Y=\prod_{j \in \mathcal{J}}\left(Q_{j}^{S}\right)^{\zeta_{j}}
$$

where $\zeta_{j}$ is the share of intermediate good produced in zone $j$ in the total cost of $Y$, and $\sum_{j \in \mathcal{J}} \zeta_{j}=1$. The associated minimum cost function is: 
where the auxiliary parameter $\omega$ is:

$$
c(Y)=Y \underbrace{\left(\prod_{j \in \mathcal{J}} p_{j}^{\zeta_{j}}\right)\left(\sum_{j \in \mathcal{J}} \omega_{j}\right)}_{\text {marginal cost }},
$$

$$
\omega_{j}=\frac{\zeta_{j}^{\left(\sum_{k \neq j} \zeta_{k}\right)}}{\prod_{k \neq j} \zeta_{k} \zeta_{k}}
$$

The conditional factor demand for each intermediate can be derived using Shephard's lemma. This is:

$$
Q_{j}^{D}=\frac{\partial c(Y)}{\partial p_{j}}=\zeta_{j} Y p_{j}^{\zeta_{j}-1}\left(\prod_{k \neq j} p_{k}^{\zeta_{k}}\right)\left(\sum_{j \in \mathcal{J}} \omega_{j}\right)
$$

Capital and labor are not used in the combining process.

\subsection{Developers}

A competitive, representative developer produces homogenous residential space, $H$, using capital $(K)$ and land $(X)$. We assume a Cobb-Douglas production function:

$$
H_{i}^{S}=K^{\theta} X^{1-\theta}
$$

Just like the ordinary firms, the firms in the construction sector make zero profits in equilibrium. This implies the following housing price per unit of floor space:

$$
p_{H i}=\underbrace{\left\{\left(\frac{\theta}{1-\theta}\right)^{1-\theta}+\left(\frac{1-\theta}{\theta}\right)^{\theta}\right\}}_{\widetilde{\Phi}} R^{\theta} p_{L i}^{1-\theta} .
$$

Again, Shephard's lemma can be used to derive the conditional factor demands for capital:

$$
K_{i}^{D_{d}}=\widehat{\Phi} \theta R^{\theta-1} p_{L i}^{1-\theta} H_{i}^{S}
$$

and land:

$$
X_{i}^{D}=\widehat{\Phi}(1-\theta) R^{\theta} p_{L i}^{-\theta} H_{i}^{S}
$$

where the supply of land in each zone is exogenous and equal to $\bar{X}_{i}$.

\subsection{Transport}

The volume-delay function is assumed to be linear in road links. That is, the time required to traverse the road link $l_{R}^{(s e)}$ using a private mode is: 


$$
t_{R}^{s e}=\ell_{R}^{s e}\left(\xi_{0 R}^{s e}+\xi_{1 R}^{s e} d_{R}^{s e}\right)
$$

where $\ell_{R}^{s e}$ and $d_{R}^{s e}$ are the length and demand (see below) of link $l_{R}^{(s e)}$ respectively, $\xi_{0 R}^{s e}$ is the free-flow travel time per unit of distance (i.e. the inverse of the free-flow speed) and $\xi_{1 R}^{s e}$ is the marginal delay caused by an additional unit of traffic in the link. Public transport $(P)$ links are not subject to congestion, therefore:

$$
t_{P}^{s e}=\ell_{P}^{s e} \xi_{0 P}^{s e}
$$

Total demand for road link $l_{R}^{(s e)}$ is:

$$
d_{R}^{s e}=N \sum_{\mathbf{a} \in \mathcal{C}}\left\{I\left(l_{R}^{(s e)} \mid q\right) P_{\mathbf{a}} D_{W \mathbf{a}}^{*}\right\}
$$

where the indicator function $I\left(l_{R}^{(s e)} \mid q\right)$ takes the value one if the route $q$ embodied in alternative $\mathbf{a}=$ $\{i, j, q\}$ contains the road link $l_{R}^{(s e)}$ (zero if not, or if a does not imply any commuting). ${ }^{13}$ The marginal external congestion cost (mecc) in link $l_{R}^{(s e)}$ is the time delay caused by an additional unit of traffic (that is $\left.\ell_{R}^{s e} \xi_{1 R}^{s e}\right)$, multiplied by the expected value of time in the link, which is denoted by $\mathbb{E}\left(v, \ell_{R}^{s e}\right) .{ }^{14}$ That is:

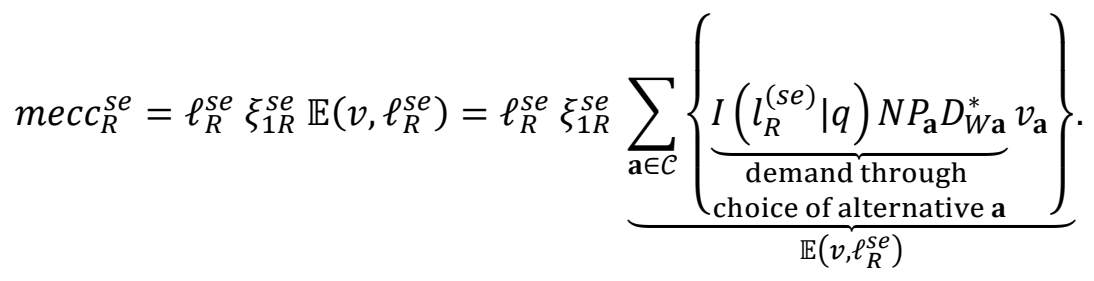

The aggregation of (70) across all links of a feasible route $q$ yields the resulting route-specific travel time:

$$
\hat{t}_{q}=\sum_{\left(\ell_{R}^{S R}, \ell_{P}^{\text {se }}\right) \in q} t_{m}^{s e} \quad \text { with } m=(R, P)
$$

The sum of the pecuniary and toll cost of route $q$ embodied in alternative $\mathbf{a}$ is:

$$
c_{\mathbf{a}}+\tau_{R \mathbf{a}}=\underbrace{(p_{g} \underbrace{\sum_{R}^{s e}}_{\ell_{R q}^{s e} \in q})+(p_{P} \underbrace{\sum_{P}^{s e} \in q}_{L_{P q}} \ell_{P}^{s e})}_{c_{\mathbf{a}}}+\underbrace{\sum_{\ell_{R}^{s e} \in q} \tau_{R}^{s e}}_{\tau_{R \mathbf{a}}},
$$

\footnotetext{
${ }^{13}$ Because private vehicles are assumed to be identical, they all contribute equally to traffic. That is, the demand for road link $\ell_{R}^{s e}$ provided in (72) coincides with its effective traffic.

${ }^{14}$ The delay is the derivative of link travel time in (70) with respect to the demand (i.e. the load) in the link.
} 
where $L_{R q}$ is the total distance generated by car in route $q$; the sum denoted by $L_{P q}$ is the total distance generated by public transport in route $q ; p_{g}$ and $p_{P}$ are the monetary costs per unit of distance when commuting by car and public transport respectively; $\tau_{R}^{\text {Se }}$ is the road toll imposed to the commuter that uses the road link $l_{R}^{(s e)}$. Weighting the first component of (75) across alternatives yields the total transport expenditure in the economy, i.e.:

$$
E_{T}=N\left(p_{g} \sum_{\mathbf{a} \in \mathcal{C}} P_{\mathbf{a}} D_{W \mathbf{a}}^{*} L_{R q}+p_{P} \sum_{\mathbf{a} \in \mathcal{C}} P_{\mathbf{a}} D_{W \mathbf{a}}^{*} L_{P q}\right),
$$

where $q$ refers to the commuting route of alternative $\mathbf{a}=\{i, j, q\}$. The model disregards fuel subsidies and public transport deficits. ${ }^{15}$ Thus, it is implicitly assumed that the expenditure in (76) is exactly equal to the cost of public transport provision, road maintenance and the value of the imported vehicles and fuel.

\subsection{Government and public budget}

The government functions as a benevolent planning authority who controls the tax instruments $\tau_{L}$ and $\tau_{R}^{S e}$, as well as the redistribution instruments $B$ and $B_{\ell}$ in order to maximize the expected maximum utility in (56). ${ }^{16}$ The expected government revenue from the labor tax is:

$$
R_{L}=\tau_{L} \underbrace{N \sum_{\mathbf{a} \text { C }}\left(P_{\mathbf{a}} D_{W \mathbf{a}}^{*} w_{j}\right)}_{\text {total labor supply (LS) }}
$$

The total revenue from road taxes is:

$$
R_{R}=N \sum_{\mathbf{a} \in \mathcal{C}}\left\{P_{\mathbf{a}}\left(\sum_{\ell_{R}^{s e} \in q} \tau_{R}^{s e}\right) D_{W \mathbf{a}}^{*}\right\}
$$

The total (equilibrium) revenue from the $J$ land markets is:

$$
B_{\ell}=\sum_{i \in \mathcal{J}} p_{L i} X_{i}^{D}
$$

Public budget is balanced, therefore:

\footnotetext{
${ }^{15}$ Public transport deficits are present in the case of The Netherlands and many OECD countries. The choice to abstract from them allows to examine the interactions between a distortionary tax and a set of spatially-interrelated externality taxes in isolation from additional inefficiencies whose role in the determination of results is peripheral.

${ }^{16}$ Because the marginal utility of income is constant across alternatives, maximization of (56) subject to the equilibrium conditions (as described in Section 3) can be achieved without alternative-specific redistribution instruments that aim to equalize the marginal utility of income across alternatives (see Anas, 2012). Furthermore, the choice facilitates the computation of compensating variations from the policies being examined. While computing such welfare measures is straightforward with income effects off, it has been shown to be a particularly cumbersome task in discrete choice settings allowing for income effects. For a complete discussion of the issue see Herriges and Kling (1999), as well as Dagsvik and Karlström (2005).
}

Second-best road taxes in polycentric networks with distorted labor markets 


$$
B=\frac{1}{N}\left(R_{L}+R_{R}\right)
$$

\subsection{General, stochastic user equilibrium}

In equilibrium, labor, housing, land markets at each zone clear, together with the output market. The expected aggregate labor supply to zone $j$ is:

$$
E\left(L_{j}^{S}\right)=N \sum_{\mathbf{a} \in \mathcal{C}}\left\{I(j \mid \mathbf{a}) P_{\mathbf{a}} D_{W \mathbf{a}}^{*}\right\},
$$

where $I(j \mid \mathbf{a})$ is an indicator function that takes the value one if the employment zone of alternative a is zone $j$ (zero otherwise). For each of the $J$ labor markets, the clearing condition is:

$$
E\left(L_{j}^{S}\right)-L_{j}^{D}=0
$$

where $L_{j}^{D}$ is the aggregate labor demand from (60). Similarly, the expected aggregate demand for housing in zone $i$ is:

$$
E\left(H_{i}^{D}\right)=N \sum_{\mathbf{a} \in \mathcal{C}}\left(I(i \mid \mathbf{a}) P_{\mathbf{a}} s_{\mathbf{a}}^{*}\right),
$$

where $I(i \mid \mathbf{a})$ is an indicator function that takes the value one if the residential zone of alternative $\mathbf{a}=$ $\{i, j, q\}$ is zone $i$ (zero otherwise) for each of the $J$ housing markets, the clearing condition is:

$$
H_{i}^{S}-E\left(H_{i}^{D}\right)=0
$$

where $H_{i}^{S}$ is the aggregate housing supply in the same zone. Land markets also clear, therefore from (69):

$$
X_{i}^{D}-\bar{X}_{i}=0
$$

where the aggregate land demand $X_{i}^{D}$ coincides with the land demand of the representative developer in (69) and $\bar{X}_{i}$ denotes the total surface available for development in zone $i$. Clearing of the intermediate $J$ markets implies that:

$$
Q_{j}^{D}-Q_{j}^{S}=0
$$

The aggregate expected demand for the composite good in the entire region is given by:

$$
E\left(Y^{D}\right)=N \sum_{\mathbf{a} \in \mathcal{C}}\left(P_{\mathbf{a}} y_{\mathbf{a}}^{*}\right)
$$


In order for the model to close properly, a part of the composite output must be used to import the required capital, and to cover the costs associated with the use of private modes and the public transport system. This implies the closure (trade balance) condition: ${ }^{17}$

$$
\underbrace{p\left(Y^{S}-E\left(Y^{D}\right)\right)}_{\text {value of exports }}=\underbrace{R\left(\sum_{j \in \mathcal{J}} K_{j}^{D_{f}}+\sum_{i \in \mathcal{J}} K_{i}^{D_{d}}\right)}_{\text {total value of imported capital }}+E_{T} .
$$

Because the equilibrium is competitive, the prices of all final and intermediate goods produced in the region equal their marginal cost. For each of the $J$ intermediates this implies one zero profit condition as in (59). Similarly, for each of the $J$ housing markets this implies a zero profit condition as in (67). Because the price of the composite is normalized to one, the corresponding condition for this good is:

$$
\left(\prod_{j \in \mathcal{J}} p_{j}^{\zeta_{j}}\right)\left(\sum_{j \in \mathcal{J}} \omega_{j}\right)=1,
$$

where $\omega$ has been defined in (64).

Finally, the disaggregate labor supply in (50), housing demand in (48) and consumption (computed from (46)-(49)) are based on a belief for the travel time attached to each alternative a. Because these underlie the aggregate labor supply, housing demand and consumption, in equilibrium the above belief has to be correct. This implies that, for each alternative $\mathbf{a}$, it holds that the commuting time belief $\left(t_{q}\right)$ is equal to the resulting commuting time given by (74). This is: ${ }^{18}$

$$
\hat{t}_{q}-t_{q}=0
$$

Section 3 describes a system of 34 types of equations in 34 vectors of unknowns. These are equations: (46), (48), (49), (50), (51), (56), (57), (59), (60), (61), (65), (67), (68), (69), (70), (71), (72), (74), (75), (76), (77), (78), (79), (80), (81), (82), (83), (84), (85), (86), (87), (88), (89), and (90). They corresponding unknown vectors are: $y_{\mathrm{a}}^{*}, s_{\mathrm{a}}^{*}, D_{W \mathrm{a}}^{*}, T_{F \mathrm{a}}^{*}, V_{\mathrm{a}}^{*}, P_{\mathrm{a}}$ (with the size of each vector equal to the number of elements in the choice set, denoted by $\left.N_{\mathcal{C}}\right), p_{j}, w_{j}, E\left(L_{j}^{S}\right), L_{j}^{D}, K_{j}^{D_{f}}, Q_{j}^{D}, p_{H i}, K_{i}^{D_{d}}, X_{i}^{D}, E\left(H_{i}^{D}\right)$, $H_{i}^{S}, p_{L i}$ and $Q_{j}^{S}$ (each vector of size equal to $J$ ), $t_{q}, c_{q}$ and $\hat{t}_{q}$ (each vector of size equal to the number of feasible routes, i.e. $N_{Q}$ ), $t_{R}^{s e}$ and $d_{R}^{s e}$ (of size equal to the number of road links in the network, $N_{R}$ ), $t_{P}^{s e}$ (of size equal to the number of public transport, i.e. rail, links, $N_{P}$ ), $R_{L}, R_{R}, B_{\ell}, B, E\left(Y^{D}\right), Y, E_{\max }, E_{T}$ and $p$ (each of size one). The model uses a network with $N_{R}=52$ road links, $N_{P}=50$ rail links, $N_{Q}=$ 1738 feasible routes, $J=18$ zones and $N_{\mathcal{C}}=N_{Q}+J=1756$ alternatives. ${ }^{19}$

\footnotetext{
${ }^{17}$ The term on the left hand side of (88) is the value of the composite good (with price, $p$, normalized to one) that is not consumed inside the region but bought by a virtual trader that exports it to the rest of the world $(R O W)$. The trader then buys capital and transport services (demanded by individuals, firms and developers in the region) of equal value from $R O W$ and sells them back to the region.

${ }^{18}$ However, it can be seen that the above holds if the expected travel times and pecuniary costs of links in the network are equal to the resulting ones.

${ }^{19}$ The model considers 12386 non-cyclical routes of which 10648 are excluded: i) due to abnormal travel time/distance compared to the shortest path route or ii) because they violate the rule of a logical mode use (e.g.
} 
Table 1. Benchmark equilibrium.

\begin{tabular}{lc} 
Key endogenous variables & Expected value (standard deviation) \\
Consumption share of income & $0.597(0.097)$ \\
Housing expenditure share of income & $0.319(0.055)$ \\
Transportation expenditure share of income & $0.084(0.057)$ \\
Duration of working day (hours) & 8.00 (fixed) \\
Labor supply (days) & $222.4(58.8)$ \\
One way commuting time (minutes) & $34.9(14.6)$ \\
Value of time (as a fraction of net wage) & $0.648(0.217)$ \\
Equilibrium-to-free-flow travel time ratio & $1.605(0.38)$ \\
Car free flow speed ( $k m / h$ ) & 70.0 \\
Public transport mode speed (km/h) & 50.0 \\
Cost of car use (E/km) & 0.207 \\
Private cost of public transport (E/km) & 0.095 \\
Car choice probability & 0.655 \\
Labor income tax rate & 0.40 \\
Key elasticities (general equilibrium) & \\
Elasticity of labor supply (w.r.t. labor tax) & \\
Car kilometers (own) & \\
Car kilometers (cross) & $-0.375(0.315)$ \\
Passenger kilometers (own) & -0.257 \\
Passenger kilometers (cross) & 0.076 \\
Responses of the modal split & -0.232 \\
Car choice probability to 10\% increase in fuel costs & 0.237 \\
Car choice probability to 10\% increase in fares & \\
\hline Notes The no & \\
\end{tabular}

Notes: The numbers in the parentheses provide the standard deviation of a corresponding variable across alternatives or highway links.

\section{Application to the area of Randstad: key data and calibration.}

The model is calibrated to fit a series of stylized facts characterizing the behavior of the average household (expenditures shares, allocation of time, etc.) and the characteristics of Randstad region: the general spatial lay-out and network, the population and employment share of each zone, the average commuting speed of modes during peak hours and the modal split. In order to ensure that the research question can be addressed without disturbing the computational tractability of the model, a resolution that comprises 18 zones has been chosen. As shown in Figure 1, each zone represents a group of municipalities, which share similar commuting patterns. ${ }^{20}$ The four largest employment and residential

routes that imply car use at two different, non-subsequent trip components: from $a$ to $b$ by car, from $b$ to $c$ by public transportation and from $c$ to $d$ by car).

${ }^{20}$ An initial selection excluded municipalities with population below 20000 inhabitants. A first grouping of municipalities into clusters (zones) was made in order to merge neighboring municipalities with populations between 20000 and 180000 inhabitants that share similar spatial labor supply patterns (towards municipalities with a population over 180000 inhabitants). 
centers (Amsterdam, Utrecht, Rotterdam and The Hague) constitute separate zones. ${ }^{21}$ The primary data used in the calibration consist of commuting flows between the eighteen zones of the model. The $18 \times 18$ origin-destination (hereafter, $O D$ ) matrix has been computed using CBS microdata for fully employed workers in year 2012. The variation of labor supply across different $O D$-pairs is not observed.

In equilibrium, the expected shares of consumption, housing and transport expenses in total expenditure are aligned with the profile of an average household in Western Europe. The expected annual labor supply in the equilibrium is 222 days, which accounts for a five-day working week, a harmonized unemployment rate of $6.5 \%$ in The Netherlands (OECD, 2017) and part of a 25-day annual leave entitlement. ${ }^{22}$ The within-day unit of time measurement is fixed to 8.0 hours. As a result, the expected one-way commuting time is approximately 33 minutes, with a standard deviation of 13 minutes.

Table 2. Residential and employment percentages in model's benchmark equilibrium and data.

\begin{tabular}{lllll}
\hline Zone & $\begin{array}{l}\text { Residential } \\
\text { share }\end{array}$ & $\begin{array}{l}\text { Residential } \\
\text { share (data) }\end{array}$ & $\begin{array}{l}\text { Employment } \\
\text { share }\end{array}$ & $\begin{array}{l}\text { Employment } \\
\text { share (data) }\end{array}$ \\
\hline Amsterdam \& Amstelveen & 0.147 & 0.148 & 0.183 & 0.182 \\
southeast Amsterdam suburbs & 0.023 & 0.021 & 0.016 & 0.012 \\
east Amsterdam suburbs & 0.012 & 0.011 & 0.015 & 0.015 \\
northeast Utrecht suburbs & 0.040 & 0.037 & 0.035 & 0.038 \\
east Utrecht suburbs & 0.035 & 0.036 & 0.032 & 0.035 \\
Utrecht & 0.047 & 0.050 & 0.061 & 0.062 \\
southwest Utrecht suburbs & 0.013 & 0.011 & 0.012 & 0.009 \\
southeast Utrecht suburbs & 0.030 & 0.028 & 0.028 & 0.025 \\
Almere \& Lelystad & 0.038 & 0.038 & 0.030 & 0.027 \\
northeast Rotterdam suburbs & 0.041 & 0.039 & 0.036 & 0.034 \\
Rotterdam & 0.101 & 0.102 & 0.125 & 0.124 \\
southeast Rotterdam suburbs & 0.076 & 0.073 & 0.054 & 0.056 \\
cluster between Rotterdam and the Hague & 0.120 & 0.124 & 0.106 & 0.107 \\
the Hague & 0.078 & 0.081 & 0.094 & 0.094 \\
Leiden and suburbs & 0.048 & 0.048 & 0.039 & 0.038 \\
cluster around Schiphol airport & 0.054 & 0.053 & 0.068 & 0.070 \\
northwest Amsterdam suburbs & 0.049 & 0.051 & 0.036 & 0.039 \\
northeast Amsterdam suburbs & 0.049 & 0.050 & 0.032 & 0.033 \\
\hline
\end{tabular}

${ }^{21}$ The included zones are: 1) Amsterdam and Amstelveen, 2) municipalities between Amsterdam and Utrecht across highway A2, 3) eastern suburbs of Amsterdam along highway A1, including Diemen, Muiden, Weesp and Naarden, 4) cluster of municipalities from Bussum, all the way on A1 to the crossing with A27, and across A27 all the way to Utrecht, 5) The cluster of Amersfoort, Soest and Zeist, municipalities located across A1 and A28 to the northeast of Utrecht, 6) Utrecht, 7) west suburbs of Utrecht (Montfoord, Woerden) across A12, 8) South suburbs of Utrecht (IJsselstein, Houten, Nieuwegein, Vianen) across A2 and A27, 9) Almere and Lelystad on A6, 10) northeast suburbs of Rotterdam, built around A12 and A20, 11) Rotterdam, 12) southeast suburbs of Rotterdam around A15, 13) municipalities located between Rotterdam and the Hague (e.g. Delft, Zoetermeer), 14) the Hague, 15) municipalities located north of the Hague, around Leiden, which are accessed through A4 and A44, 16) municipalities located southwest of Amsterdam (Haarlem, Haarlemermeer), with the area including Schiphol airport, 17) cluster of municipalities located across A9 from Haarlem up to Alkmaar, and 18) northwest suburbs of Amsterdam (Zaanstad, Purmerend) accessed through parts of A10, A8 and A7.

${ }^{22}$ This is the mean harmonized unemployment rate recorded in The Netherlands between January 2014 and July 2017. 
Figure 1. Spatial configuration of the model: zonal aggregation (left), main highways of the road network (middle) and network representation (right).

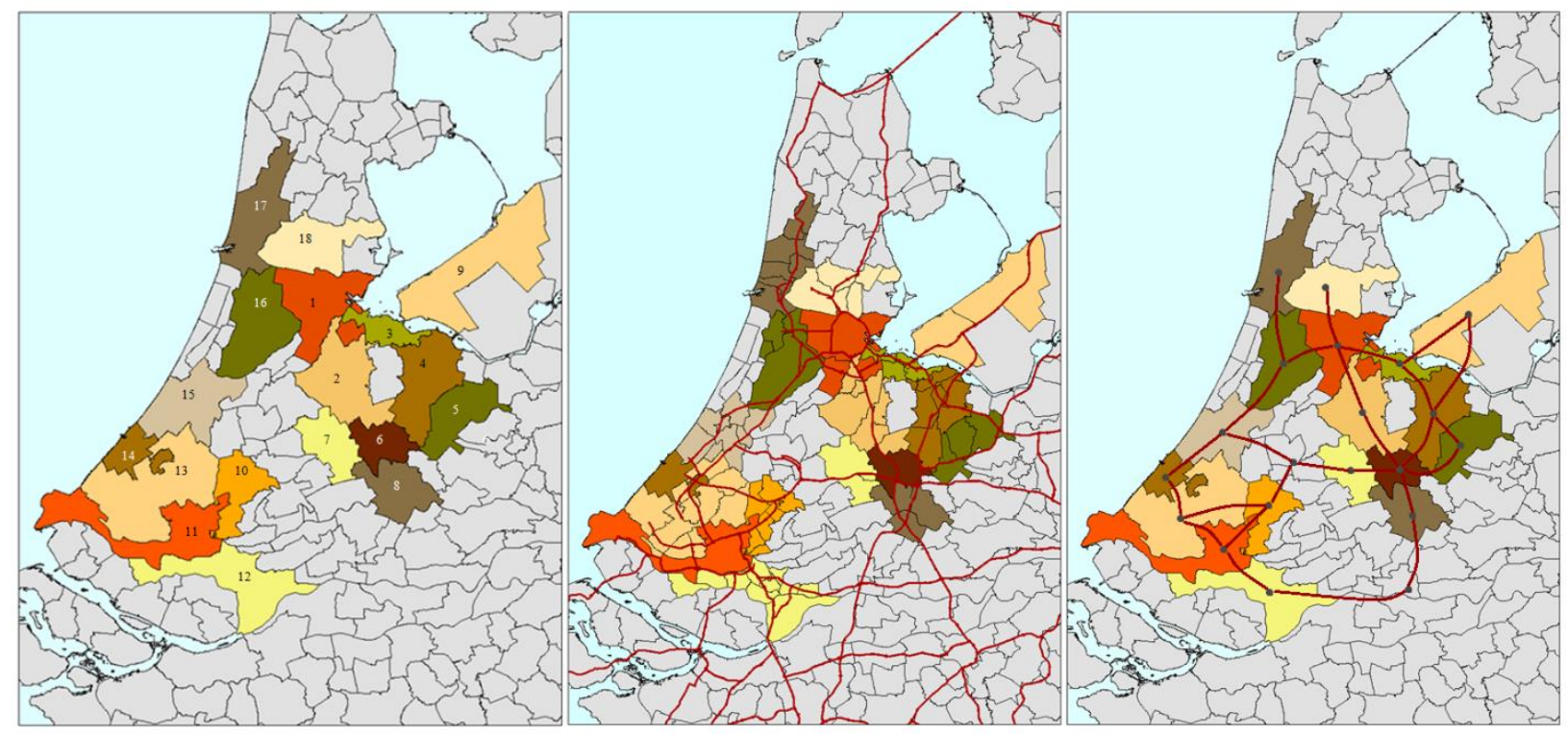

It is assumed that the free-flow speed of private vehicles is $70 \mathrm{~km}$ per hour across the entire network, in line with assumptions made in earlier contributions, e.g. Van Dender (2003). ${ }^{23}$ This speed accounts for bottlenecks, traffic lights and other delaying factors in the intercity highways that are not modeled explicitly in this application. It also considers the fact that intercity commuting in the region involves, inevitably, driving inside urban areas, where free-flow speed is by definition substantially lower. In equilibrium, the expected car speed falls to $43.6 \mathrm{~km} / \mathrm{h}$, which is also in alignment with commuting speeds observed outside The Netherlands, for instance the one reported for large US cities in the national household travel survey (Federal Highway Administration, 2004). Public transportation is assumed to be congestion-free and is served with a constant speed of $50 \mathrm{~km}$ per hour. In equilibrium, the probability of commuting by car is 0.655 , which is representative of the observed modal split in The Netherlands. Commutes that combine car and public transport are rather unlikely (roughly $2.6 \%$ ). ${ }^{24}$ The pecuniary cost of car use $\left(p_{g}\right)$ is approximately $0.207 € / \mathrm{km} .{ }^{25}$ This cost is in accordance with the use of a compact car with an assumed lifetime of $200000 \mathrm{~km}$, a lifetime cost of $€ 25000$ (i.e. purchase price plus

\footnotetext{
${ }^{23}$ The free-flow parameter $\xi_{0 R}$ has been fixed to 0.72321 . Multiplying that parameter with 8.0 hours, i.e. the withinday unit of time measurement, yields approximately 5.79 hours per unit of distance. This implies a speed of 0.17284 units of distance per hour. Finally, setting the unit of distance equal to $405 \mathrm{~km}, \xi_{0 R}$ implies a free-flow speed of 70 $\mathrm{km}$ per hour. The assumption of homogeneous free-flow speeds is justified by a national highway speed limit and the highly-aggregated nature of the network representation used in this study. This representation smooths most of the cross-link variation in speed limits or infrastructure that could give rise to substantial cross-link variation in freeflow speeds.

${ }^{24}$ See Schwanen et al. (2001) for an analysis of the modal split and urban form based on the Dutch National Travel Survey of 1998.

${ }^{25}$ Exogenous price $p_{g}$ is set to 0.12 monetary units per unit of distance $(405 \mathrm{~km})$, implying 0.000296 monetary units per kilometer. The expected daily wage (after tax) in equilibrium is 0.1934 monetary units, which correspond to $€ 135.14$, i.e. the assumed after-tax income of $€ 30000$ divided by the equilibrium labor supply of 222 days. Dividing 0.000296 by 0.1934 and multiplying with $€ 135.14$ yields a car use cost of approximately $0.207 € / \mathrm{km}$. A similar calculation yields a cost of $0.095 € / \mathrm{km}$ for the use of public transport.
} 
maintenance), an average consumption per kilometer (e.g. 0.065 liters) and a plausible gasoline price per liter (e.g. $€ 1.50$ ). The corresponding kilometer price for public transport is $€ 0.095$. $^{26}$

The parameters are calibrated in order for the employment and population shares of each zone to fit those observed in data. ${ }^{27}$ Table 2 juxtaposes the employment and residential shares in the benchmark equilibrium against the respective shares observed in data. The benchmark equilibrium is computed with a uniform labor income tax rate set at $40 \%$, which is the rate faced by the average commuter in The Netherlands and is in accordance with the labor income tax rates in many OECD countries. The role of this rate in the determination of the results (Section 5) is explored with extensive sensitivity analysis, i.e. by examining the stability of the findings within a wide range of tax rates $(5 \%-60 \%)$.

The fixed cost of the public transport operator is set to zero in benchmark equilibrium. There are no price subsidies in public or private transport, thus pricing is assumed to be efficient. The expected value of time is approximately 0.65 of the net, after-tax wage, with a standard deviation of 0.217 . These values are in line with those proposed at several previous studies (Small, 2012). The general equilibrium elasticity of labor supply, which varies across alternatives in the choice set, has an expected value of 0.375 and a standard deviation of 0.314 . This value is in accordance with the values proposed for The Netherlands in the meta-analysis by Evers et al. (2008) and lies slightly below the upper quartile of elasticities reported in the study by Hansson and Stuart (1985).

The general equilibrium elasticity of private vehicle kilometers with respect to the pecuniary cost of car use is -0.257 , in line with recent meta-analysis results (Dimitropoulos et al., 2016) and sufficiently close to the long-run elasticity proposed by Goodwin et al. (2004). Similarly, the cross-elasticity of public transport kilometers (with respect to the pecuniary cost of car use), which is shown to be a key determinant of the results in Section 5, is 0.237. That is in line with the values proposed in Acutt and Dodgson (1996). In the benchmark, a 10\% increase in the pecuniary cost of car use reduces the car choice probability by approximately 3.0 percentage points; similarly, a $10 \%$ increase in the fares of public transport increases the cap choice probability by 0.8 percentage points. Appendix $\mathbf{C}$ provides a complete enumeration of the model's exogenous variables and parameters (including their values).

\section{Policy analysis}

This section examines a series of policy interventions whose relevance is not limited to Randstad but extends to general polycentric networks subject to severe traffic externalities during commuting hours. Each policy considered consists of two parts. The first component is a tax rule, i.e. a formula that assigns a value to each externality tax in the network. The tax rule encapsulates partial taxation by defining which externality taxes will be fixed to zero. It may also contain the bounds of an externality tax, e.g. it may be constraint to positive values. The second component of a policy is its revenue recycling type, which can be either lump-sum or labor tax cuts. In the former case, the total revenue from the distortionary tax and the externality tax is returned in the form of a lump-sum transfer to households. In the latter case, the total revenue from externality taxation is returned in the form of a cut in the distortionary tax. Therefore,

\footnotetext{
${ }^{26}$ This price may initially appear as low, but is plausible when someone considers: (i) the various discounts (at least $20 \%$ ) available to commuters with seasonal subscriptions, (ii) the various types of public transport subsidies available to the labor force in The Netherlands and (iii) a ceiling annual price of $€ 3$ 996, all factors that are not modelled explicitly in this study.

${ }^{27}$ The study abstracts from agglomeration effects. Therefore, $A_{j}$ is set to 1.0 in each zone.
} 
policies involving labor tax cuts are essentially revenue-neutral tax swaps, since the total tax revenue remains intact.

The discussion is organized as follows. Section 5.1 describes all policies examined in the paper, providing their tax rule and their revenue recycling type. Section $\mathbf{5 . 2}$ discusses the numerical results from the application of the various policies in the benchmark equilibrium, as the latter was described in Section 4. In order to investigate the degree to which the results presented in Section $\mathbf{5 . 2}$ are context-specific, two types of sensitivity analyses are pursued. Section $\mathbf{5 . 3}$ explores the sensitivity of the findings with respect to the level of the distortionary tax. In that section, the numerical results of Section $\mathbf{5 . 2}$ are revisited in a wide range of labor income tax rates (from 0.05 to 0.60 ) without a recalibration of the model. Section $\mathbf{5 . 4}$ attempts a deeper, comparative sensitivity analysis, in which the model is recalibrated to produce a highly elastic substitution pattern between leisure and labor and a fairly inelastic substitution pattern between the use of car and public transport. The alternative equilibrium is characterized by an (average) elasticity of labor supply that lies in the upper bound of the values proposed in literature, as well as cross elasticities of substitution in the lower bound of values found in the literature. The policy analysis pursued in that section is relevant both from a theoretical and a practical point of view, as it highlights the case in which a corrective tax set at its Pigouvian level turns out to be welfare decreasing, even when it is part of a revenue-neutral tax swap.

Table 3. Specification of policies considered in the paper.

\begin{tabular}{|c|c|c|c|c|}
\hline Policy & Tax rule & Coverage & $\begin{array}{l}\text { Revenue } \\
\text { recycling* }\end{array}$ & Auxiliary information \\
\hline Base & $\tau_{R}^{s e}=0$ for all $l_{R}^{(s e)}$ & & Lump-sum & \\
\hline$F N P-L S$ & $\tau_{R}^{s e}=m e c c_{R}^{s e}$ for all $l_{R}^{(s e)}$ & Full network & Lump-sum & $\tau_{R}^{s e}$ is set to its Pigouvian level \\
\hline$D P C-L S$ & $\tau_{R}^{s e}=\left\{\begin{array}{l}\bar{\tau}_{R e} \text { if } e \in \mathcal{T} \\
0 \text { otherwise }\end{array}\right.$ & Partial & Lump-sum & $\begin{array}{l}\text { Each } \bar{\tau}_{R e} \geq 0 ; \overline{\boldsymbol{\tau}}_{R} \text { maximizes } \\
(56)\end{array}$ \\
\hline$F K T-L S$ & $\tau_{R}^{s e}=p_{D} \ell_{R}^{(s e)}$ & Full network & Lump-sum & $p_{D} \geq 0 ; p_{D}$ maximizes $(56)$ \\
\hline$F N P-T C$ & $\tau_{R}^{s e}=\operatorname{mecc}_{R}^{s e}$ for all $l_{R}^{(s e)}$ & Full network & Tax cuts & $\tau_{R}^{s e}$ is set to its Pigouvian level \\
\hline$D P C-T C$ & $\tau_{R}^{s e}=\left\{\begin{array}{l}\bar{\tau}_{R e} \text { if } e \in \mathcal{T} \\
0 \text { otherwise }\end{array}\right.$ & Partial & Tax cuts & $\begin{array}{l}\text { Each } \bar{\tau}_{R e} \geq 0 ; \overline{\boldsymbol{\tau}}_{R} \text { maximizes } \\
\text { (56) }\end{array}$ \\
\hline$F K T-T C$ & $\tau_{R}^{s e}=p_{D} \ell_{R}^{(s e)}$ & Full network & Tax cuts & $p_{D} \geq 0 ; p_{D}$ maximizes $(56)$ \\
\hline$S L S-x$ & $\tau_{R}^{s e}=\left\{\begin{array}{cl}\tau_{R s e} & \text { if } l_{R}^{(s e)} \in \mathcal{S}_{x} \\
0 & \text { otherwise }\end{array}\right.$ & Partial & Tax cuts & $\tau_{R s e} \lesseqgtr 0 ; \overline{\boldsymbol{\tau}}_{R}$ maximizes $(56)$ \\
\hline$S L E-x$ & $\tau_{R}^{s e}=\left\{\begin{array}{cl}\tau_{R s e} \text { if } l_{R}^{(s e)} \in \mathcal{E}_{x} \\
0 \text { otherwise }\end{array}\right.$ & Partial & Tax cuts & $\tau_{R s e} \lesseqgtr 0 ; \overline{\boldsymbol{\tau}}_{\boldsymbol{R}}$ maximizes (56) \\
\hline FNO-TC & $\tau_{R}^{s e}$ is free for all $l_{R}^{(s e)}$ & Full network & Tax cuts & $\overline{\boldsymbol{\tau}}_{\boldsymbol{R}}$ maximizes (56) \\
\hline
\end{tabular}

Notes: $\mathcal{T}=\{1,6,11,14\}$ (See Section 4 for more information about these nodes); $\ell_{R}^{(s e)}$ denotes the length of road link from start node $s$ to end node $e ; \mathcal{S}_{x}$ denotes the set containing the $x$ slowest road links (in the benchmark 
equilibrium); $\mathcal{E}_{x}$ denotes the set containing the road links with the $x$ highest marginal external costs of congestion (in the benchmark equilibrium); ${ }^{*}$ Revenue recycling of the road tax revenue.

\subsection{Summary of policies}

Table 3 summarizes the policies examined in the paper. In the base equilibrium, the toll in each road link is set to zero and the labor income tax rate is 0.40 . The income tax revenue is returned lump-sum. The full network Pigouvian toll (denoted by FNP) imposes a Pigouvian tax rule in the entire network, i.e. the value of the corrective tax $\tau_{R}^{S e}$ is set to its Pigouvian level in all links of the network. Two versions of the policy are considered: FNP-LS, in which the road tax revenue is returned lump-sum, and FNP-TC in which the road tax revenue finances a cut in $\tau_{L}{ }^{28}$ The differentially priced set of cordon tolls (DPC-LS and DPC-TC in Table 3) imposes a non-negative toll in every road link $l_{R}^{(s e)}$ whose endpoint $e$ leads to a location in the set $\mathcal{T}$. In this application, $\mathcal{T}$ contains the four largest cities of Randstad (Amsterdam, Utrecht, Rotterdam and The Hague). The policy allows the non-negative toll to be differentiated by the endpoint of the link, i.e. the cordon surrounding each city could be priced differently $\left(\right.$ e.g. $\bar{\tau}_{R e^{\prime}}=\tau_{R}^{s e^{\prime}} \neq$ $\tau_{R}^{s e}=\bar{\tau}_{R e}$ for $\left.e^{\prime}, e \in \mathcal{T}\right)$ but links setting up the same cordon are charged equally $\left(e . g . \tau_{R}^{s^{\prime} e}=\tau_{R}^{s e}=\bar{\tau}_{R e}\right.$ for $e \in \mathcal{T}$ ). Under a flat kilometer tax (denoted by FKT-LS and FKT-TC in Table 3), every road link on the network is charged a price that is proportional to its length, $\ell_{R}^{(s e)}$.

In addition to the aforementioned tax rules, the study considers less structured forms of partial taxation that allow a more general selection of links. Such selected links are not related strongly in spatial terms the way links in policies involving cordons are. In a selection of links based on speed, (denoted by $S L S-x$ in Table 3) the $x$ most congested links in the network (see (70)), i.e. the links with the highest equilibrium-to-free-flow travel time ratio, are considered for a toll that is free to obtain negative values. Similarly, a selection of links based on the external effects (denoted by SLE- $x$ in Table 3) considers the road links with the $x$ highest marginal external cost of congestion (see (73)) for a toll that is free to obtain negative values. The following sections display results based on selections of 10, 20 and 35 links (i.e. the results from policies $S L S-10, S L S-20, S L S-35$, SLE-10, SLE-20 and SLE-35), in which the aforementioned tax rule is combined with a labor tax-cut revenue recycling.

Finally, the full network optimum (denoted by FNO-TC in Table 3), also referred to as the optimal tax reform, allows all links to be charged a toll that is free to obtain any positive or negative value, with the net revenue used to finance a cut in the labor income tax. Because of its flexibility, the policy generates the largest possible gains a revenue-neutral tax reform can generate. Thus, it is used as a benchmark, against which the efficiency of each of aforementioned policy is compared.

\subsection{Core findings}

Table 4 displays the results from the various policies imposed on the benchmark equilibrium, as the latter was presented in Section 4.

\footnotetext{
${ }^{28}$ Although recycling the tax revenues in a lump-sum manner would be a peculiar policy in reality, such transfers facilitate an isolation of the distortionary effects of labor taxation from other inefficiencies related to the provision of a public good. While the inclusion of a public good has provided useful insights in other settings without tax interactions (see for instance Anas and Pines, 2012), here it would complicate the analysis while being peripheral to the main focus of the paper.
} 
While the Pigouvian toll is the most efficient intervention in a setting where road traffic externalities pose the only inefficiency, a series of contributions have shown that substantial welfare losses may occur from a marginal external cost pricing rule in the presence of a pre-existing distortionary tax that remains intact (Parry and Bento 2001; Tikoudis et al., 2015a). ${ }^{29}$ In all these settings, the Pigouvian effect of the road tax, here expressed by its network counterpart in (22), falls short of the negative tax interaction effect, as expressed in (23), at the margin of the base equilibrium, in which road tolls are zero. As a result, the optimal value of the corrective tax does not only lie below its Pigouvian level, here expressed in (73), but is essentially negative. In line with those findings, the full network Pigouvian toll with revenue returned lump-sum $(F N P-L S)$ is found to cause considerable welfare losses that account for $0.66 \%$ of the after-tax income. ${ }^{30}$ In Section 5.3, the welfare effect of FNP-LS is revisited in a labor income tax rate that varies between 0.05 and 0.60 .

However, Tikoudis et al. (2015a) illustrate a case in which partial taxation that takes the form of a cordon toll in a monocentric serial network may generate welfare gains even if the pre-existing labor income tax is as high as 0.40 . That result is driven by two key factors: (i) the cordon toll should be imposed in a certain distance from a central business district (i.e. the sole destination node of the model) and that (ii) the elasticity of labor supply is monotonically decreasing with distance from it. Together, these drivers ensure that those affected by the cordon toll are the individuals with the most inelastic labor supply, i.e. the population groups that generate the weakest tax-interaction effect. The cordon toll equilibrium (DPC-LS in Section 5.1) is computed in order to explore the degree to which the above result can be generalized in an urban polycentric network, like the one considered in this study. The four cordons surround Amsterdam-Amstelveen (with the corresponding node indexed by 1 in Figure 1), Utrecht (indexed by 6), Rotterdam (indexed by 11) and The Hague (indexed by 14). Cumulatively, the three nodes attract $46.2 \%$ of the labor force in the region.

At the distortionary tax at $40 \%$, the policy turns out to bear little practical relevance in the polycentric context of the benchmark equilibrium. That is, the optimal differentiated charges, $\bar{\tau}_{R e}$, are all found to be zero. This indicates that the finding by Tikoudis et al. (2015a) may be confined to monocentric city settings, as it fails to be confirmed in a less stylized, mixed polycentric network. The key difference is that Tikoudis et al. (2015a) consider a serial monocentric network where the elasticity of labor supply falls with distance from the central business district (CBD). Thus, the links located further away from (closer to) it are used exclusively by commuters with more inelastic (elastic) supply of labor. ${ }^{31}$ The tax interaction effect then fades out with distance from CBD, rendering a cordon toll the appropriate scheme to charge eclectically the inelastic portion of labor supply, something that is not possible in a mixed polycentric network. Furthermore, the optimal flat kilometer charge in FKT-LS is also found to be zero, as the policy taxes all links positively.

Put together, the results from the three policies discussed so far (FNP-LS, DPC-LS, FKT-LS) indicate that, in the presence of the benchmark labor income tax rate (e.g. 40\%), conventional road pricing during the peak commuting hours is unlikely to generate the considerable welfare gains it is hoped for. It has to either incorporate a sophisticated revenue-recycling program, e.g. labor tax cuts

\footnotetext{
${ }^{29}$ To the knowledge of the author, this is the first study to approach the issue using real data from a general (i.e. not serial) polycentric network.

${ }^{30}$ Assuming an annual after tax income of $€ 30000$, this welfare loss is $€ 198$ per capita.

${ }^{31}$ Apart from the spatial configuration, the present setting differs from Tikoudis et al. (2015) in other respects, as the latter considers income effects, endogenizes city size but disregards household heterogeneity.
} 
(alternatively, public transport subsidies which are not considered explicitly in this study), or a nonconventional tax rule that is flexible enough to subsidize the use of car in specific parts of the network.

To some extent, the above finding depends on the way labor market is modelled. In general, if labor supply is elastic in the extensive margin (number of days) but inelastic in the intensive margin (duration of the working day) the resulting negative tax interaction effect is stronger compared to the case in which labor supply is adjustable in both margins. ${ }^{32}$ Furthermore, the model does not consider a timevarying toll, which is shown to flatten traffic levels across different time intervals of the peak commuting hours. Such a scheme allows the commuters with the smallest schedule-delay costs, i.e. the most flexible in terms of arrival time, to use the road links relatively cheaper. To the extent that the elasticity of labor supply is considerably higher in these groups, the above results may overstate the magnitude of the tax interaction effect.

Table 4. Welfare effects of policies imposed on the benchmark equilibrium

\begin{tabular}{|c|c|c|c|c|}
\hline Policy* & $\begin{array}{l}\text { Compensating variations } \\
\text { (\% of income })\end{array}$ & Relative efficiency & $\tau_{L}$ & Relative labor supply \\
\hline Base & - & - & 0.4 & 1.0 \\
\hline$F N P-L S$ & $0.658 \%$ & -0.884 & 0.381 & 0.98843 \\
\hline$D P C-L S$ & $0 \%$ & 0 & 0.4 & 1.0 \\
\hline$F K T-L S$ & $0 \%$ & 0 & 0.4 & 1.0 \\
\hline$F N P-T C$ & $-0.639 \%$ & 0.872 & 0.3812 & 1.00782 \\
\hline$D P C-T C$ & $-0.473 \%$ & 0.646 & 0.3835 & 1.00623 \\
\hline$F K T-T C$ & $-0.573 \%$ & 0.783 & 0.381 & 1.00723 \\
\hline SLS-10 & $-0.402 \%$ & 0.549 & 0.3888 & 1.00433 \\
\hline$S L S-20$ & $-0.598 \%$ & 0.816 & 0.3817 & 1.00749 \\
\hline$S L S-35$ & $-0.700 \%$ & 0.956 & 0.3783 & 1.00886 \\
\hline SLE-10 & $-0.382 \%$ & 0.521 & 0.3881 & 1.00506 \\
\hline SLE-20 & $-0.566 \%$ & 0.773 & 0.3822 & 1.00752 \\
\hline SLE-35 & $-0.690 \%$ & 0.942 & 0.3788 & 1.00879 \\
\hline$F N O-T C$ & $-0.733 \%$ & 1.0 & 0.378 & 1.009323201 \\
\hline
\end{tabular}

Notes: *See section 5.1 for the description of each coded policy.

Finally, the present study does not model explicitly non-commuting traffic, which generates externalities during the peak hours, without being subject to a tax-interaction effect. A part of that traffic,

\footnotetext{
${ }^{32}$ This becomes clearer when public transport is removed from the model. Then, in the former case the bases of the labor and road tax overlap completely; in the latter case the overlap is only partial, since labor supply (in total hours) is not proportional to the number of commuting trips. An in-depth analysis of the above issue is attempted by Hirte and Tscharaktschiew (2015). De Borger (2009) investigates optimal congestion taxes in a wage bargaining model with unemployment. It is shown that, compared to a competitive labor market environment, optimal transport taxes differ substantially in a setting where firms bargain with labor unions.
} 
consisting mainly of leisure and shopping trips, is not distinguishable from that related to commuting, as it is also generated by private vehicles. To the extent that this traffic accounts for a substantial part of the total on-peak traffic, the inefficiency of the archetype pricing rules discussed so far may be overstated. In fact, as leisure and shopping trips account for a larger share of the on-peak traffic, the undifferentiated optimal tolls may positive (see for instance Van Dender, 2003), rendering conventional pricing schemes more relevant, even when their revenue is returned lump-sum. In general, however, the relative contribution of such traffic is small, as leisure and shopping trips most often take place during off-peak hours or in the weekends. That relative contribution becomes even smaller when measured in terms of vehicle kilometers, as shopping trips are most often contained within city limits. This argument is particularly valid for the spatial context of this study, in which urban domains occupy only a small part of the total area into consideration.

The other type of traffic that is relevant in the analysis consists of freight transportation trips. Unlike leisure and shopping trips, this traffic interacts with commuting in the largest part of the intercity highway network considered in the study; thus, its relative contribution to the total on-peak traffic should be taken into account. However, freight traffic is easily distinguished from that generated by commuters. In that sense, the findings from the analysis of archetype policies (FNP-LS, DPC-LS, FKT-LS) are in alignment with those by Van Dender (2003), who finds the optimal toll on commuting trips to be zero when toll differentiation between commuting and non-commuting traffic is possible.

The failure of policies that recycle road tax revenue lump-sum (at the benchmark level of labor $\operatorname{tax}$ ), leads to the investigation of alternative policies that return the revenue in the form a labor tax cut. Because the labor tax is distortionary to begin with, this cut generates a revenue-recycling effect (see Section 2). When the latter effect is strong enough to offset the tax interaction effect, a second dividend emerges.

The final row of Table 4 displays the results from the implementation of the full network optimal toll (FNO-TC), which allows the toll in every road link to acquire any value, even a negative one. ${ }^{33}$ This intervention bears interest because it provides the benchmark against which other second-best interventions can be compared. The results (see Appendix B) reveal that the optimal values of the corrective taxes in the network display a wide variation around their Pigouvian levels. This deviation ranges from $-340 \%$ to $+558 \%$, with the corrective tax in three of the 52 links of the network being negative. ${ }^{34}$ The second dividend emerges in 34 links; the remaining links receive a positive charge below the marginal external cost of congestion. Appendix B provides the optimal fee and the corresponding marginal external cost for each link. The collected road revenue suffices to reduce the labor income tax rate from its benchmark value, 0.40 , to 0.378 . That considerable reduction is accompanied by a nonnegligible increase in aggregate labor supply $(0.93 \%)$. With the assumptions made (Section 4) the policy is found to generate welfare gains that account for $0.733 \%$ of income. ${ }^{35}$

Apart from the full network optimal tax, exploring a series of other revenue-neutral tax swaps provides a series of insights. First, the relative efficiency of a full network Pigouvian toll (coded as FNP$T C$ ) is found to be very high $(87.2 \%)$; this is an indication that pricing externalities at their marginal

\footnotetext{
${ }^{33}$ This necessitates the exclusion of cyclical paths.

${ }^{34}$ This result is in line with Tikoudis et al. (2015a). With a parameterization similar to the one used here, it is shown that the location-based optimal road tax scheme in a monocentric city can be non-monotonic when the benchmark labor tax is high. Considering the monocentric city as a serial network with a unique destination implies that the above result can be expressed as a link-based road tax scheme in which the most distant links receive negative charges.

${ }^{35}$ Assuming an average annual after tax income of $€ 30000$, these gains correspond to approximately $€ 220$.
} 
external cost is still a highly-efficient intervention, as long as revenue recycling is used to mitigate the negative tax interactions in the background. Second, the relative efficiency of the cordon toll system (DPC-TC) is found to be substantial as well (i.e. 64.6\%) despite considerably lower than that of the Pigouvian toll. The optimal toll values display a slight variation across cities: $4.7 \%$ of the daily after-tax income for the cordon surrounding Amsterdam, 2.8\% for the respective cordon surrounding Utrecht, 3.3\% for Rotterdam and $3.6 \%$ for The Hague. The policy has the capacity to finance a substantial decrease in the labor tax (1.6 to 1.7 percentage points) and to increase labor supply, by approximately $0.6 \%$. The flat kilometer tax $(F K T-T C)$ is shown to be even more effective, as the optimal charge per kilometer (approximately $0.034 \%$ of daily income) is found to capture $78.3 \%$ of the gains generated by the optimal tax reform.

The efficiency of partial schemes that tax or subsidize the use of the slowest links in the benchmark equilibrium depends on the degree of coverage. With 35 of 52 links considered (i.e. SLS-35), relative efficiency turns out to be very high $(95.6 \%)$, but that number declines as coverage decreases: $81.6 \%$ for the twenty slowest links (i.e. SLS-20) and 54.9\% for the ten slowest (i.e. SLS-10). Similar results are found for the case in which the link selection is based on the marginal external congestion costs.

\subsection{Sensitivity analyses}

The second-best policies examined at the benchmark equilibrium are motivated by the various constraints that characterize the implementation of the optimal tax reform. Such constraints can be technical, for instance it may be costly to monitor traffic in the entire network, despite the advances in GPS technology. They may also be political, as a full network approach that leaves no alternatives untaxed may give rise to discomfort, rendering the reform highly unpopular. Also, negative tax levels at some links will be counterintuitive for the users. But, most important, the implementation of any road pricing scheme that involves subsidies requires cyclical routes to be ruled out beforehand, something that in most cases is not feasible. The sensitivity analysis presented in Figures $\mathbf{2}$ and $\mathbf{3}$ juxtaposes the importance of the distortionary tax on labor income against the inherent inefficiency of the second-best policies presented in Section 5.1.

The upper left panel of Figure 2 displays the efficiency of the three archetype policies (i.e. FNP$L S, D P C-L S$ and $F K T-L S$ ). In that panel, the vertical line at $\tau_{L}=0.4$ marks the benchmark equilibrium, with the corresponding results discussed already in Section 5.2. The results in levels $\tau_{L}$ above 0.4 are of limited interest: the optimal values of the cordon fees and the flat kilometer tax are both at their lower bound, essentially zero. Thus, no gains can be realized from $D P C-L S$ and $F K T-L S$. As the background distortion increases, FNP-LS becomes more detrimental. This is because, with road tax revenue returned lump-sum, the deviation between the optimal values and the Pigouvian levels of the externality taxes increases with the magnitude of the background distortion. On the other hand, as the distortionary tax decreases the tax interaction effects fade out and optimal externality taxes converge to their Pigouvian levels, i.e. the relative efficiency of $F N P$ - $L S$, displayed in the solid curve, approaches 1.0. The sensitivity analysis shows that the threshold $\tau_{L}$ values at which $D P C-L S$ and $F K T-L S$ begin generating welfare gains are found to lie slightly above 0.30 . As $\tau_{L}$ approaches zero, the relative efficiency of the two policies, displayed by the short- and long-dashed curves respectively, approaches to levels similar to those proposed in earlier literature (e.g. Mun et al., 2005; Verhoef, 2005).

Second-best road taxes in polycentric networks with distorted labor markets 
Figure 2. Performance of policies with lump-sum revenue recycling at different levels of labor income tax rate.
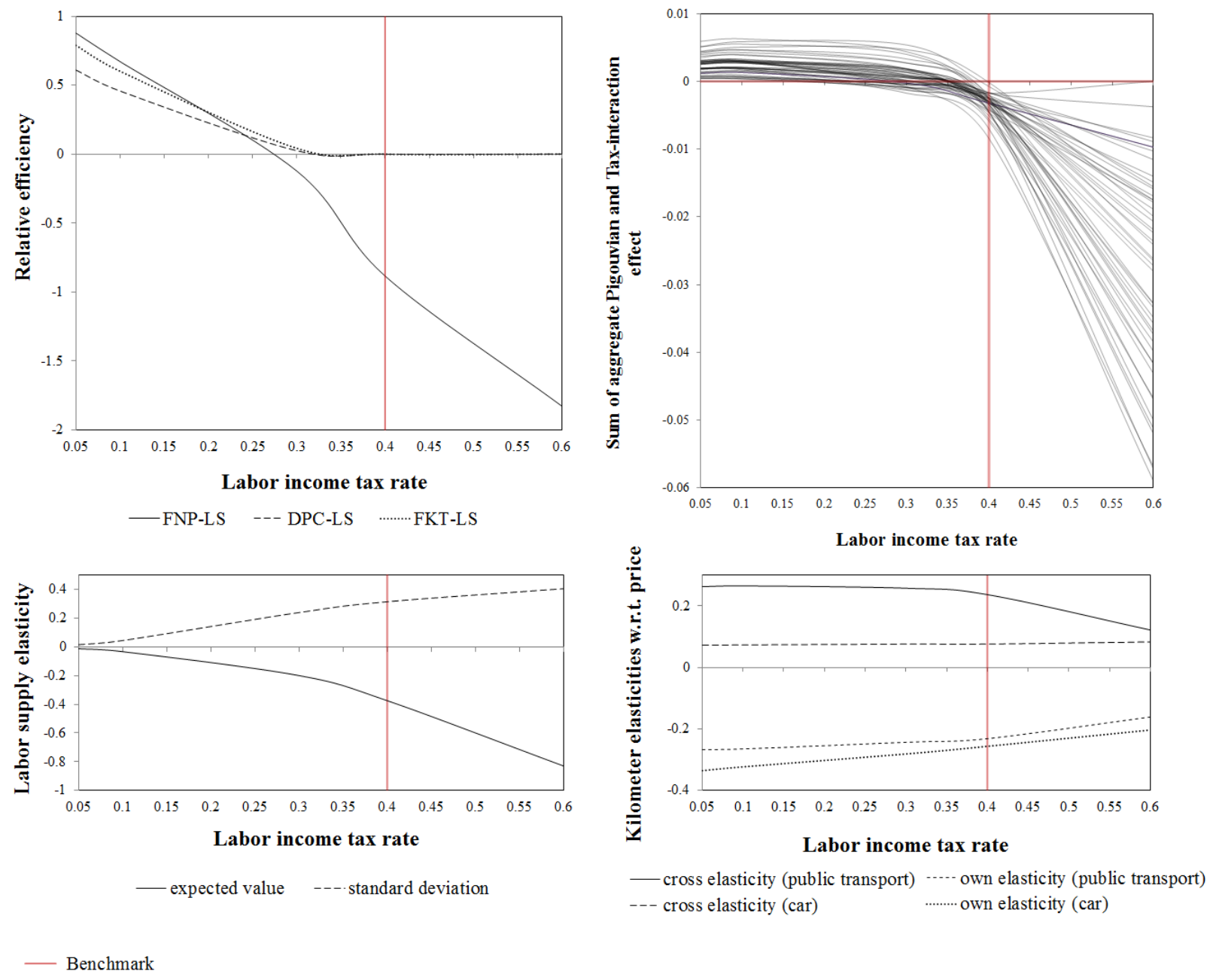

Notes: Upper left panel: Relative efficiency of FNP-LS, DPC-LS and FKT-LS; Upper right panel: sum of the approximated aggregate Pigouvian effect and tax-interaction effect in each network link, computed at the margin of the base (no-toll) equilibrium; Lower left panel: labor supply elasticity (expected value and standard deviation); Lower right panel: Own- and cross-elasticities of kilometers produced by car and public transport (with respect to the kilometer costs). 
Figure 3. Performance of policies involving labor tax cuts at different levels of initial labor income tax rate.
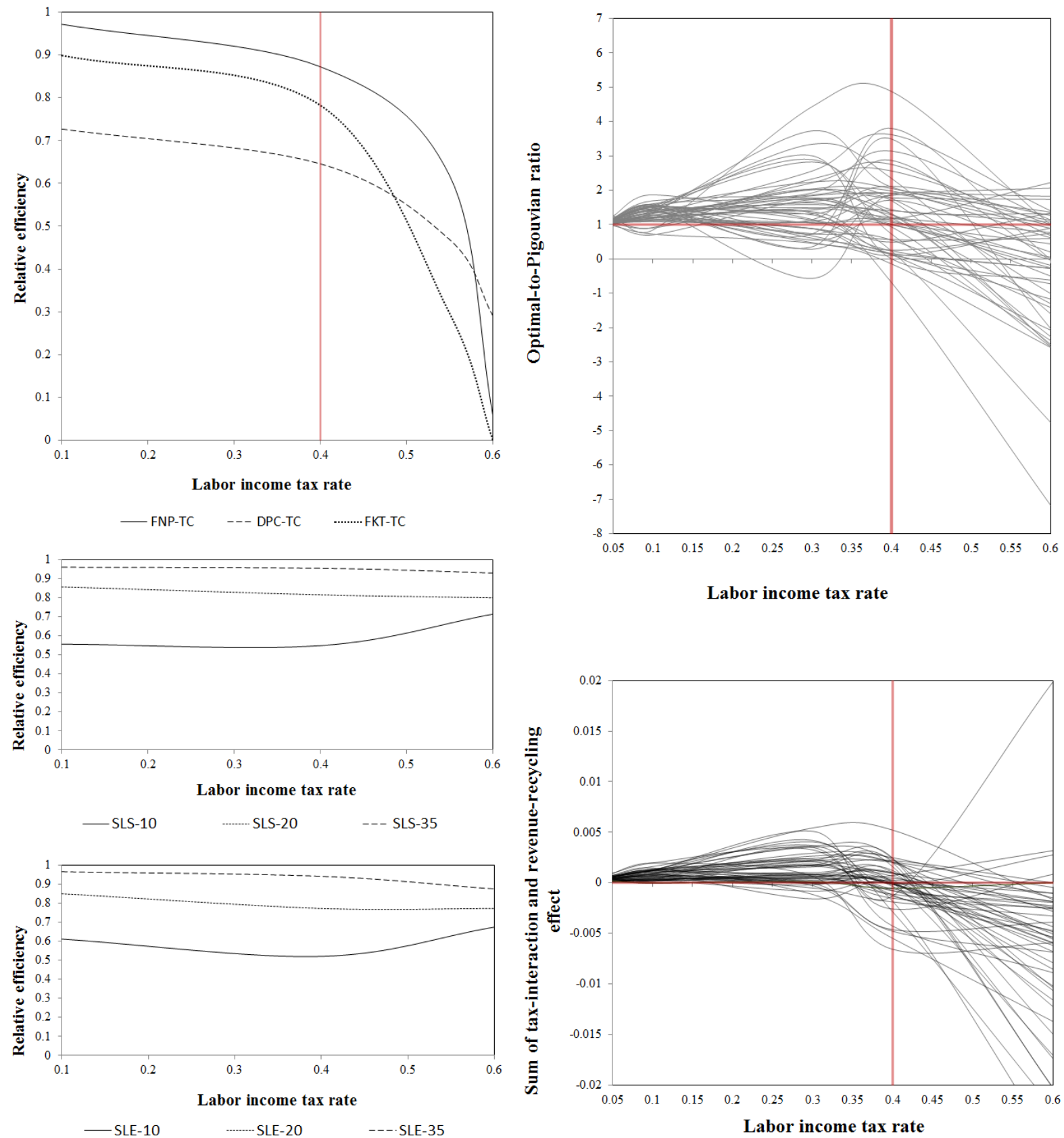

_-Benchmark"

Notes: Upper left panel: Relative efficiency of $F N P-L S, U P C-L S$ and $D P C-L S$; Middle left panel: Relative efficiency of $S L S-10, S L S-20, S L S$-35; Lower left panel: Relative efficiency of $S L E-10, S L E-20, S L E$-35; Upper right panel: Ratio between the optimal toll and the marginal external cost in each link of the network; Lower right panel: sum of the approximated tax-interaction effect and revenue-recycling effect in each network link, as approximated at the margin of the Pigouvian toll equilibrium 
To illustrate the impact of the labor income tax rate clearer, each curve in the upper right panel of Figure 2 displays the sum of the aggregate Pigouvian effect and the tax interaction effect in one link of the network. The latter effects are approximated at the margin of the base equilibrium, in which all externality taxes are set to zero, using the counterparts of formulae (22) and (23), adjusted for the numerical model. ${ }^{36}$ Roughly, a positive (negative) sum indicates that the corrective tax in the corresponding link should be positive (negative). At the benchmark equilibrium $\left(\tau_{L}=0.4\right)$ all curves lie below zero, something that corroborates the general failure of any tax rule that prices positively the use of road links when externality tax revenue is returned lump-sum. As $\tau_{L}$ approaches the upper bound used in the sensitivity analysis, i.e. 0.6, the negative tax-interaction effects grow in magnitude in all links, pulling the displayed sum to even lower levels. This implies that the optimal levels of the externality taxes will reflect, predominantly, a Ramsey component rather than a Pigouvian component. Consequently, as $\tau_{L}$ increases marginal external cost pricing becomes more detrimental. On the other hand, as $\tau_{L}$ approaches zero Pigouvian effects dominate, drawing the displayed sum to positive values. When $\tau_{L}$ falls below 0.2 the sum of the two effects becomes positive in all links of the network, indicating that the optimal tax rule should price all externalities positively. When $\tau_{L}$ is set to zero, the Ramsey component of the externality disappears and the sum reflects exclusively the aggregate Pigouvian effect.

The upper right panel of Figure 3 displays the ratio between the optimal and the Pigouvian level of an externality tax, as that ratio occurs in each road link under labor tax-cut revenue recycling. Negative values of that ratio imply a negative optimal tax and values above one indicate that a double dividend emerges in the link. Values below zero and one imply a positive optimal toll but an absence of double dividend. Each curve in the lower right panel of Figure 3 displays the sum of the tax-interaction effect and the revenue-recycling effect in one link of the network. The latter effects are approximated at the margin of the Pigouvian equilibrium, in which all externality taxes are set to their Pigouvian levels. Roughly, a positive (negative) sum indicates that the corrective tax in the corresponding link should lie above (below) its Pigouvian value.

The right panels of Figure 3 provide the necessary intuition that underlies the findings displayed in the left panels of Figure 3. In the context of a revenue-neutral tax swap, the optimal values of the corrective taxes lie much closer to their Pigouvian levels. This is because the negative tax-interaction effects are partially or entirely offset by the revenue-recycling effects, something that is not possible with lump-sum revenue recycling. A direct result is that, with revenue used in the form of labor tax cuts, the (spatial) design of the externality tax scheme becomes important even in high levels of the distortionary tax. For instance, at $\tau_{L}=0.4$ it can be seen that the efficiency loss from the inability of $D P C-T C$ to perform marginal external cost pricing (roughly, the vertical distance between DPC-TC and FNP-TC) is larger than the efficiency loss caused from the fact that $\tau_{L}$ remains positive despite the tax swap (roughly, the vertical distance between FNP-TC and 1.0). However, when the distortionary tax is far above its benchmark value (e.g. at $\left.\tau_{L}=0.6\right)$ tax-interaction effects grow enough to cause the optimal values of the corrective tax in several road links to be negative (upper right panel of Figure 3). In that case, the flat kilometer tax and the full network Pigouvian toll become irrelevant. On the other hand, the relative efficiency of the cordon toll system remains substantial. This is because DPC-TC leaves untaxed several of the road links that are priced negatively under the full network optimum (FNO-TC) but receive positive charges under FKT-TC and FNP-TC.

\footnotetext{
${ }^{36}$ That is, the expressions of $\tilde{L}_{\mathbf{a x}}$ and $V_{\mathbf{a} x}$ in (13) and (14) are now expanded to account for all channels (except for $\tau_{L}$ ) through which labor supply can be adjusted in the model presented in Section 3 (e.g. through housing and output prices, wages). Similarly, the marginal excess burden is computed in the general equilibrium of the expanded model.
} 
Table 5. Elasticities in the alternative benchmark equilibrium.

$\begin{array}{lc}\text { Key elasticities (general equilibrium) } & \\ \text { Elasticity of labor supply (w.r.t. labor tax) } & -0.541(0.344) \\ \text { Car kilometers (own) } & -0.026 \\ \text { Car kilometers (cross) } & 0.008 \\ \text { Passenger kilometers (own) } & -0.023 \\ \text { Passenger kilometers (cross) } & 0.033 \\ \text { Responses of the modal split } & \\ \text { Car choice probability to 10\% increase in car use costs } & -0.01699 \\ \text { Car choice probability to 10\% increase in fares } & 0.00794\end{array}$

Notes: The rest of the equilibrium's characterization is in line with that of the benchmark equilibrium in Table 1.

Figure 4. Relative performance of policies involving labor tax cuts (alternative calibration).
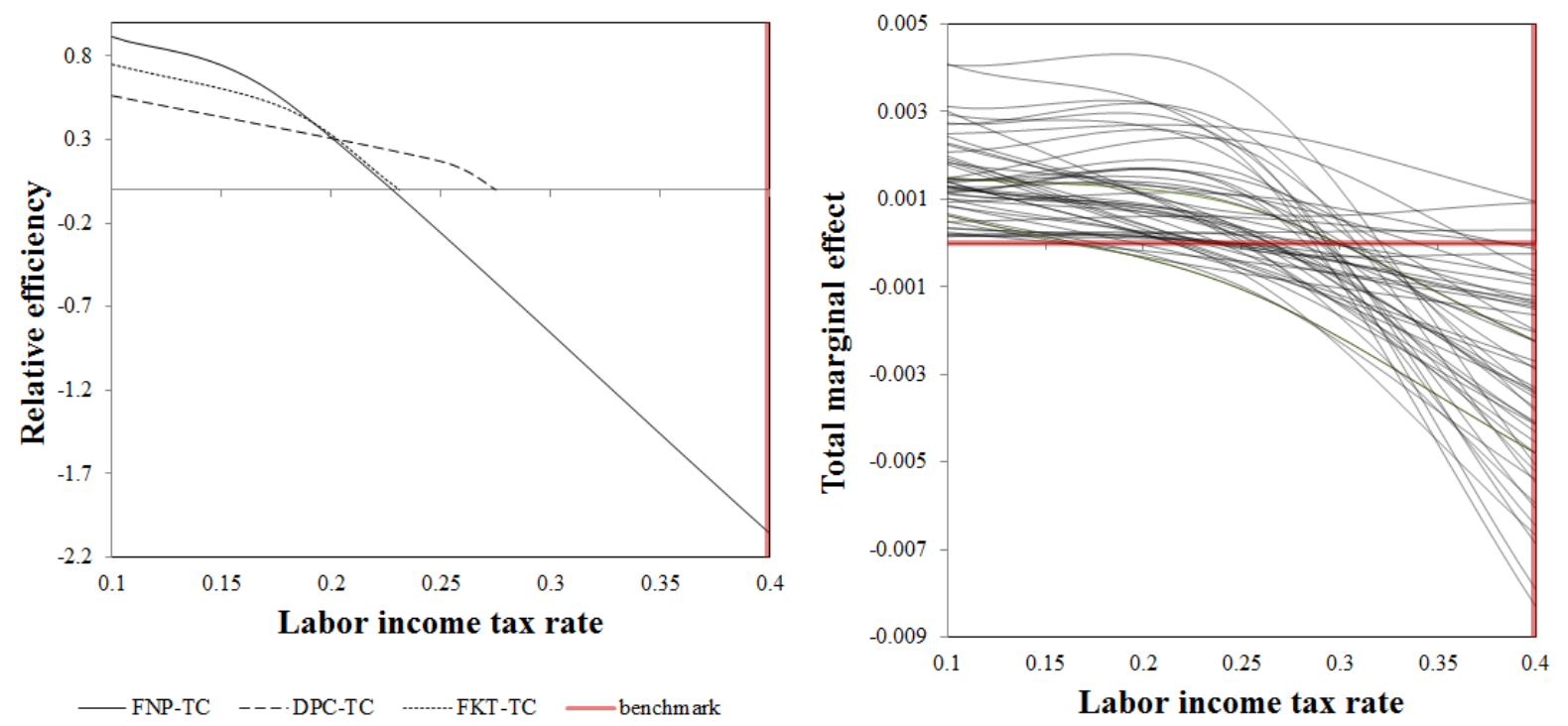

\subsection{A special case}

The results displayed in Sections $\mathbf{5 . 2}$ and $\mathbf{5 . 3}$ assume that the elasticity of labor supply lies within a range of values that are roughly in line with those proposed by Evers et al. (2008) for The Netherlands. Furthermore, the various transportation elasticities obtained plausible values (Acutt and Dodgson, 1996).

This section attempts a deeper sensitivity check, in which the model is recalibrated to give rise to an elasticity of labor supply that lies closer to the upper bound of the values proposed in literature $(-0.54)$. Furthermore, as shown in Table 5, the alternative benchmark equilibrium is characterized by substantially lower cross-elasticities in transportation. In particular, the passenger kilometers generated with public transport vehicles respond very inelastically to changes in the kilometer cost of car use, with the cross-elasticity at 0.033 . Also, a $10 \%$ increase in the kilometer cost of car use shifts the modal split towards public transportation by approximately 1.7 percentage points (versus 3.0 percentage points in the benchmark of Section 4). Exploring the impact of low cross-elasticities in the results is important because, in many cases, parts of urban areas are not well-covered by public transportation. That can be the 
outcome of low frequency of service, long walking distances to public transportation nodes and several other factors captured implicitly by the mode specific constants (see (53) and (54)), which in turn govern the cross-elasticities. For the rest, the characterization of the new benchmark equilibrium resembles that of the respective equilibrium presented in Section 4.

The left panel of Figure 4 displays the relative performance of a full-network Pigouvian toll (solid line), the system of cordon tolls (long-dashed line) and the flat kilometer tax (short-dashed line), all accompanied by tax-cut revenue recycling. The findings are particularly surprising: even if the revenue is used to reduce the labor tax, all archetype schemes fail to generate welfare gains at tax levels above $28 \%$. Most important, marginal external cost pricing becomes particularly detrimental, i.e. it generates losses even at tax levels below 25\%. As shown in the right panel of Figure 4, the tax-interaction effect dominates the Pigouvian and the revenue-recycling effect (at the margin of the base equilibrium) in the vast majority of links in the network.

The finding bears significant policy implications. First, it highlights that optimizing the externality taxes from an environmental point of view may not only be suboptimal but also welfarereducing, even if the revenue from externality taxation is recycled in an optimal way. In turn, this suggests that using the optimal type of revenue recycling does not automatically imply that the taxinteraction effects can be ignored in policy design. The principle setting the externality taxes (e.g. an environment or transportation ministry) cannot fully dedicate itself to getting the Pigouvian levels of the corrective taxes right, even if the revenue from the externality taxes reduces the revenue that has to be raised by distortionary taxation. The approximation of the total marginal effects in Figure 4 reveals that there may exist only few positively-priced partial taxation schemes that could generate welfare gains when the labor income tax rate is $40 \%$. Such a failure calls for more complex pricing schemes that will, inevitably, subsidize commuting in part of the network, especially the segments used by the users with the most inelastic choice of transportation mode, i.e. the users with the lowest accessibility to public transportation.

\section{Concluding remarks}

This paper derived new insights by incorporating the two core mechanisms that generate the double dividend (i.e. the tax-interaction and revenue-recycling effects) in a network setting with multiple externality-generating facilities (i.e. roads). These facilities complement or substitute each other and may be left untaxed (partial taxation). Among others, this setting facilitates the identification of circumstances under which partial taxation of these externalities may be Pareto preferred to the textbook Pigouvian remedy, not only with revenue returned lump-sum, but also in the form of a cut in the distortionary tax. The model used has a clear geographical reference, i.e. the polycentric urban conglomeration in the area of Randstad, which comprises the four largest cities of The Netherlands (Amsterdam, Utrecht, Rotterdam and The Hague).

The paper derived a series of policy-relevant insights. First, with the labor income tax rate set at $40 \%$ and the elasticities of labor supply and vehicle use (own, cross) set at plausible values, all pricing schemes that impose strictly positive charges were found to decrease welfare, unless their revenue is used to reduce the distortionary tax. To some extent, the result contrasts earlier findings showing that welfare gains from a cordon toll in a monocentric city may be possible even with the labor tax set to $40 \%$. A plausible explanation is that, as the spatial structure becomes more polycentric, cordon tolls lose part of their capacity to charge eclectically to the most inelastic parts of the labor force. That capacity may be

Second-best road taxes in polycentric networks with distorted labor markets 
high in a monocentric framework in which the elasticity of labor supply decreases with distance from the employment location; but it fades in a polycentric network in which each road link may be used by commuters with different employment destinations.

Second, when revenue is recycled lump-sum, all basic pricing schemes are found to generate welfare gains in the entire range of labor income tax rates considered (i.e. 5\% to 60\%). However, the level of the distortionary tax determines the relative efficiency of the various pricing schemes examined. As that tax increases, optimal externality taxes reflect primarily the tax-interaction and revenue-recycling effects and are very likely to be negative if the magnitude of the former effect is large. Rigid tax rules that impose positive charges to the entire network are then losing efficiency faster than partial taxation schemes that may leave part of the network untaxed. In line with this, the system of cordon tolls is found to be more efficient than marginal external cost pricing or a flat kilometer tax at the upper bound of the sensitivity analysis. On the other hand, as the distortionary tax decreases, tax-interaction effects fade out and optimal externality taxes reflect primarily the marginal external costs. Then, the relative efficiency of pricing schemes is determined by their inherent capacity to capture the spatial variation of these costs in a network.

Finally, the paper highlighted the special case in which the cross-elasticities of vehicle use are at the low bound of the values proposed in literature. With the elasticity of labor supply still within the range of plausible values, a marginal external cost pricing scheme was shown to be welfare-decreasing even with its revenue used to finance a cut in the uniform labor tax. In the same benchmark equilibrium, all pricing schemes that were restricted from imposing negative charges failed to produce welfare gains. The approximation of the corresponding double-dividend effects reveals that there may exist only few positively-priced schemes that could generate welfare gains. The result suggests that the optimal form of revenue recycling does not automatically imply that the tax-interaction effects can be ignored; thus, policy design cannot fully dedicate itself to getting the Pigouvian levels of the corrective taxes right.

To some extent, the limitations of the current study indicate a series of future research challenges. That is, the two behavioral margins not considered explicitly in this paper, i.e. the adjustment of the working day duration and the choice of departure time, may affect the magnitude of the tax-interaction effect. Allowing for the former adjustment may deflate the tax-interaction effect because commuting trips cease to be proportional to labor time, i.e. the same labor can be supplied with longer, but fewer working days (and thus commuting trips). Allowing for the latter may deflate the tax-interaction effect, especially if the elasticity of labor supply is positively correlated with arrival time flexibility. In that case, a timevarying toll may sort commuting traffic, with the most elastic parts commuting at the lower peak, thus facing a relatively lower toll that generates smaller tax-interaction effects. Finally, the paper has focused on commuting trips, i.e. the predominant form of traffic in the urban motorways during the peak-hour, disregarding other forms of traffic (e.g. shopping) that are not subject to a tax-interaction effect. Therefore, policy makers should interpret the results having in mind the aforementioned limitations, which should be taken into account in a less stylized type of policy analysis. To the extent that the level of tax-interaction effects can be computed correctly, the sensitivity analyses of this study provide several insights on how to design a welfare improving road tax scheme in a polycentric network.

Second-best road taxes in polycentric networks with distorted labor markets 


\section{Acknowledgements}

I would like to express my gratitude to Professors Alex Anas, Erik Verhoef, Jos van Ommeren for their constructive and influential comments in earlier versions of the paper, as well as Professors Kay Axhausen, John Rust and Kenneth Judd for their useful insights during presentations of this work. The feedback from participants in: the North American Regional Science Council conference (Atlanta, November 2013), the 2nd conference of the European Association for Research in Transportation (Stockholm, September 2013), the poster session during the Zurich Initiative for Computational Economics (Zurich, February 2014), the meetings of i-PriSM project, the kick-off meeting of BREATHE project (Amsterdam, April 2016), the seminars in Tinbergen Institute and Swiss Federal Institute of Technology (ETH) is highly appreciated. The author is indebted to the Netherlands Organization for

Scientific Research (NWO Grant 434-09-021) and to the European Research Council (AdG Grant \#246969 OPTION) for financial support.

Second-best road taxes in polycentric networks with distorted labor markets 


\section{Technical appendices}

\section{Appendix A: notation and terminology}

Table A1. Variables, prices and policy instruments

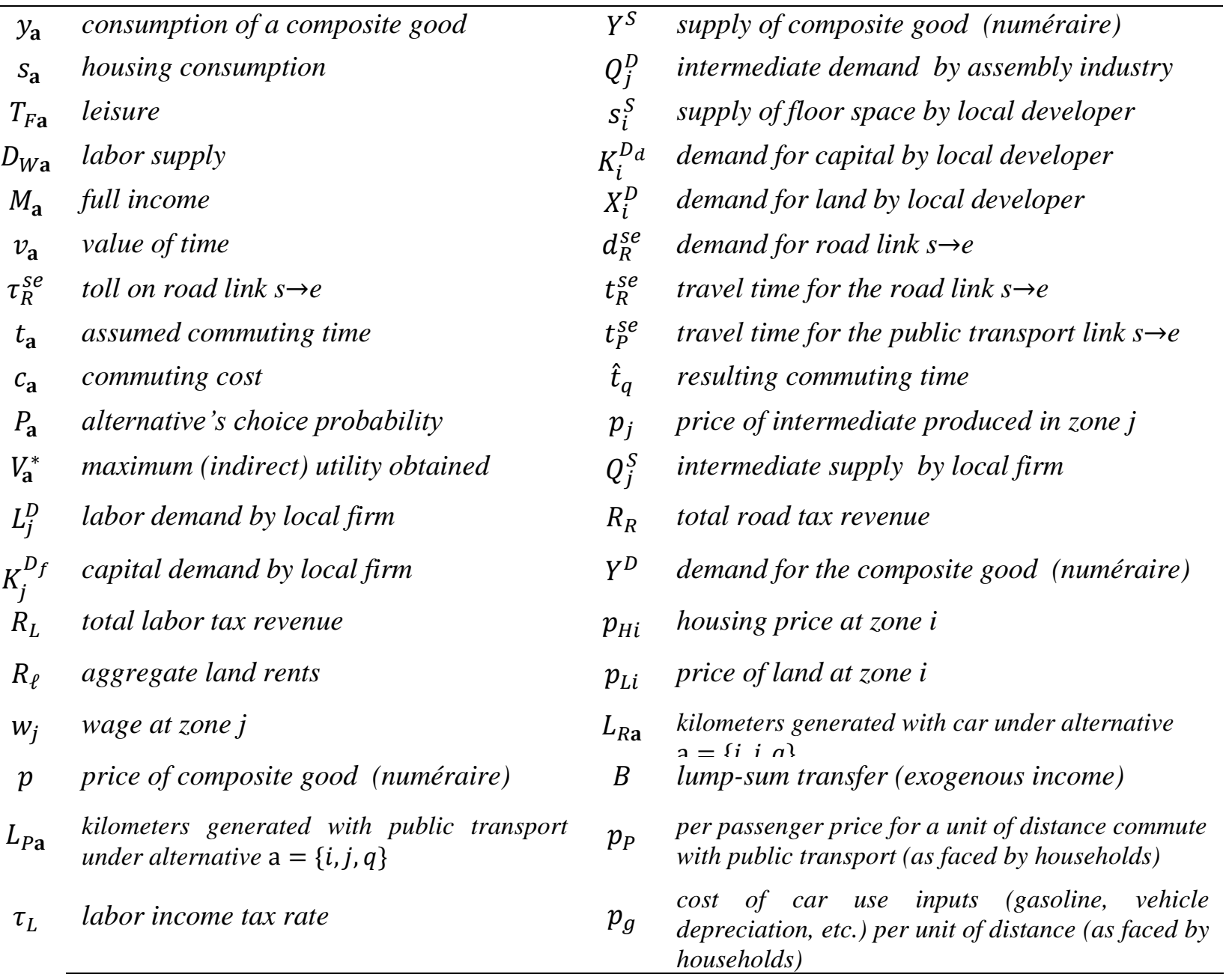

Notes: the subscript a denotes that the variable is conditional on the choice of a given alternative. Every route $q$ corresponds to a unique alternative $\mathbf{a}$, subscripts that refer to a specific route $q$ can be replaced by $\mathbf{a}$ (e.g. $L_{R \mathbf{a}}=$ $\left.L_{R q}\right)$.

Second-best road taxes in polycentric networks with distorted labor markets 
Table A2. Network and choice notation

\begin{tabular}{|c|c|c|c|}
\hline $\mathcal{J}$ & an order set of J zones & $i$ & an index pointing at the $i$-th zone of $\mathcal{J}$ \\
\hline$j$ & an index pointing at the $j$-th zone of $\mathcal{J}$ & $\mathcal{C}_{O D}$ & $\begin{array}{l}\text { a set of all possible origin-destination } \\
\text { pairs }\end{array}$ \\
\hline$a_{i j}$ & $\underset{i \rightarrow i}{\text { an arbitrary origin-destination pair }}$ & $l_{m}^{(s e)}$ & $\begin{array}{l}\text { an arbitrary link from node s to node e with } \\
\text { transport mode } m\end{array}$ \\
\hline$q$ & $\begin{array}{l}\text { route: a sequence of neighboring links } \\
l_{m}^{(s e)}\end{array}$ & $\ell_{m}^{s e}$ & the length of link $l_{m}^{(s e)}$ \\
\hline $\mathcal{Q}\left(\mathrm{a}_{i j}\right)$ & $\begin{array}{l}\text { the set of all routes } q \text { that are compatible } \\
\text { to } \mathrm{a}_{i j} \text {, i.e. they depart from the } i \text {-th zone } \\
\text { and terminate to the } j \text {-th zone }\end{array}$ & $\mathbf{a}$ & $\begin{array}{l}\text { alternative: an arbitrary origin destination } \\
\text { pair, } \mathrm{a}_{i j} \text {, coupled with a route } q \in \mathcal{Q}\left(\mathrm{a}_{i j}\right) \text {. } \\
\text { Denoted as } \mathrm{a}=\left\{\mathrm{a}_{i j}, q\right\}=\{i, j, q\}\end{array}$ \\
\hline $\mathcal{C}$ & $\begin{array}{l}\text { Choice set containing all possible } \\
\text { alternatives }\end{array}$ & $I\left(l_{m}^{(s e)} \mid q\right)$ & $\begin{array}{l}\text { indicator function that equals one if route } \\
q \text { contains link } l_{m}^{(s e)} \text { and zero otherwise }\end{array}$ \\
\hline$I(j \mid \mathrm{a})$ & $\begin{array}{l}\text { indicator function that equals one if } \\
\text { alternative a implies the } j \text {-th zone of } \mathcal{J} \text { as } \\
\text { destination }\end{array}$ & $I(i \mid \mathrm{a})$ & $\begin{array}{l}\text { indicator function that equals one if } \\
\text { alternative a implies the } i \text {-th zone of } \mathcal{J} \text { as } \\
\text { origin }\end{array}$ \\
\hline
\end{tabular}

Table A3. Definition of key concepts

$\begin{array}{ll}\begin{array}{l}\text { Correctivelexternality } \\ \text { tax }\end{array} & \begin{array}{l}\text { A tax imposed on an externality-generating commodity or facility (e.g. road } \\ \text { toll) }\end{array} \\ \text { Distortionary tax } & \begin{array}{l}\text { A tax imposed on the consumption of a commodity or the supply of a production } \\ \text { factor that does not generate an externality (e.g. labor tax). }\end{array}\end{array}$

Pigouvian equilibrium The equilibrium that occurs when all correctivelexternality taxes are set to their Pigouvian levels. In the context of the paper, the road toll is set equal to the marginal external cost of congestion in every road link.

Pigouvian level of a The level of a tax that is equal to the marginal external cost of the correctivelexternality corresponding commodity or facility that is subject to the tax.

$\operatorname{tax}$

Pigouvian tax/toll A correctivelexternality tax or toll whose value has been set to its Pigouvian level

Partial taxation The case in which the values of one or more of the corrective taxes are fixed to zero (e.g. several road links in a network cannot be taxed).

Full taxation

The case in which none of the values of the corrective taxes is fixed to zero. 
Optimal level of a corrective/externality $\operatorname{tax}$

First-best equilibrium

Quasi first-best

Pigouvian equilibrium

Second-best equilibrium
The level of an arbitrary correctivelexternality tax that maximizes welfare given the values of the rest of the corrective and distortionary taxes. Under full taxation and when all distortionary taxes are set to zero, optimal and Pigouvian levels of all corrective taxes coincide.

The equilibrium occurring from setting all distortionary taxes equal to zero and all corrective taxes to their Pigouvian levels, i.e. a Pigouvian equilibrium without tax-induced distortions.

Any equilibrium in which all corrective taxes are set to their Pigouvian levels but distortionary taxes are not set to zero.

Any equilibrium in which all adjustable taxes are set to their optimal levels, given any fixed levels of the non-adjustable taxes or any constraint in the total tax revenue.

\section{Appendix B: Optimal tax reform on the benchmark}

Table B1. Optimal toll and marginal external congestion cost (by link) in the case of labor tax cut revenue recycling.

\begin{tabular}{llllllll}
\hline start & end & Optimal toll & mecc & start & end \\
node & node & & & Optimal toll & mecc \\
1 & 3 & 0.004633 & 0.002603 & 3 & 1 & 0.004267 & 0.003037 \\
1 & 2 & 0.005145 & 0.002680 & 2 & 1 & 0.006188 & 0.003127 \\
1 & 16 & 0.004680 & 0.004017 & 16 & 1 & 0.005723 & 0.004738 \\
1 & 18 & 0.003916 & 0.002116 & 18 & 1 & 0.002089 & 0.003696 \\
2 & 6 & 0.003129 & 0.002810 & 6 & 2 & 0.003594 & 0.002504 \\
4 & 6 & 0.002977 & 0.002999 & 6 & 4 & 0.004330 & 0.002046 \\
5 & 6 & 0.000295 & 0.002235 & 6 & 5 & 0.002221 & 0.001175 \\
6 & 8 & 0.000995 & 0.001809 & 8 & 6 & -0.000269 & 0.001867 \\
6 & 7 & -0.001308 & 0.001904 & 7 & 6 & 0.001474 & 0.001580 \\
3 & 9 & 0.003927 & 0.001676 & 9 & 3 & 0.002462 & 0.002069 \\
3 & 4 & 0.004606 & 0.002416 & 4 & 3 & 0.003697 & 0.002885 \\
4 & 9 & 0.001397 & 0.001932 & 9 & 4 & 0.005852 & 0.001676 \\
4 & 5 & 0.000028 & 0.001373 & 5 & 4 & 0.002729 & 0.001304 \\
8 & 100 & 0.002546 & 0.000522 & 100 & 8 & 0.000256 & 0.001103 \\
12 & 100 & 0.000256 & 0.002098 & 100 & 12 & 0.002546 & 0.000993 \\
12 & 11 & 0.000418 & 0.004426 & 11 & 12 & 0.007126 & 0.002269 \\
10 & 11 & 0.000747 & 0.003193 & 11 & 10 & 0.009844 & 0.002589 \\
13 & 11 & 0.002364 & 0.004836 & 11 & 13 & 0.006263 & 0.003053 \\
13 & 14 & 0.000956 & 0.003686 & 14 & 13 & 0.007107 & 0.001964 \\
14 & 15 & 0.007154 & 0.002599 & 15 & 14 & 0.000457 & 0.003216 \\
15 & 16 & 0.000684 & 0.004285 & 16 & 15 & 0.004085 & 0.003821 \\
16 & 17 & 0.003574 & 0.002089 & 17 & 16 & 0.003839 & 0.003251 \\
15 & 101 & 0.002008 & 0.001527 & 101 & 15 & 0.001927 & 0.001908 \\
10 & 101 & -0.004167 & 0.001734 & 101 & 10 & 0.001528 & 0.001170 \\
7 & 101 & 0.008608 & 0.001308 & 101 & 7 & 0.002999 & 0.001769 \\
10 & 13 & 0.004026 & 0.002282 & 13 & 10 & 0.010247 & 0.003572 \\
\hline & & & & & & &
\end{tabular}

Second-best road taxes in polycentric networks with distorted labor markets 
Notes: Values have been computed using a $B F G S$ algorithm. Different starting values generated by the no-toll and the Pigouvian quasi first-best equilibrium were used, providing a convergence to (roughly) the same optimum.

\section{Appendix C: Replicability of simulation experiments}

The following tables provide the calibrated values of parameters used in the simulation experiments, as well as the values of the exogenous variables in the model. A vector of satisfactory initial values of the endogenous variables is available upon request.

Table C1. Values of parameters and exogenous variables

\begin{tabular}{cllllllllllllll}
\hline$\alpha$ & 0.751 & $\mathrm{z}_{P}$ & -4.40 & $\zeta_{11}$ & 0.140 & $\mathrm{z}_{I 5}$ & -0.51 & $\mathrm{z}_{I 17}$ & 2.12 & $\mathrm{z}_{J 11}$ & 2.89 & $p_{g}$ & 0.120 \\
$\beta$ & 0.249 & $\mathrm{z}_{t}$ & -14.05 & $\zeta_{12}$ & 0.040 & $\mathrm{z}_{I 6}$ & 2.10 & $\mathrm{z}_{I 18}$ & 1.49 & $\mathrm{z}_{J 12}$ & 3.98 & $p_{P}$ & 0.055 \\
$\gamma$ & 0.028 & $\zeta_{1}$ & 0.210 & $\zeta_{13}$ & 0.055 & $\mathrm{z}_{I 7}$ & -6.57 & $\mathrm{z}_{J 1}$ & 4.00 & $\mathrm{z}_{J 13}$ & 7.57 & $R$ & 0.001 \\
$\pi_{0}$ & 91.125 & $\zeta_{2}$ & 0.015 & $\zeta_{14}$ & 0.110 & $\mathrm{z}_{I 8}$ & -1.15 & $\mathrm{z}_{J 2}$ & -3.41 & $\mathrm{z}_{J 14}$ & 1.68 & & \\
$\pi_{1}$ & 198.9 & $\zeta_{3}$ & 0.015 & $\zeta_{15}$ & 0.040 & $\mathrm{z}_{I 9}$ & -1.48 & $\mathrm{z}_{J 3}$ & -2.97 & $\mathrm{z}_{J 15}$ & -0.62 & & \\
$\hat{\lambda}$ & 3.2 & $\zeta_{4}$ & 0.025 & $\zeta_{16}$ & 0.060 & $\mathrm{z}_{I 10}$ & -0.21 & $\mathrm{z}_{J 4}$ & 1.27 & $\mathrm{z}_{J 16}$ & 2.54 & & \\
$\delta$ & 0.3 & $\zeta_{5}$ & 0.025 & $\zeta_{17}$ & 0.035 & $\mathrm{z}_{I 11}$ & 4.60 & $\mathrm{z}_{J 5}$ & 0.43 & $\mathrm{z}_{J 17}$ & 0.99 & & \\
$\theta$ & 0.3 & $\zeta_{6}$ & 0.070 & $\zeta_{18}$ & 0.035 & $\mathrm{z}_{I 12}$ & 3.35 & $\mathrm{z}_{J 6}$ & 0.00 & $\mathrm{z}_{J 18}$ & -0.70 & & \\
$\xi_{0 R}^{s e}$ & 0.72321 & $\zeta_{7}$ & 0.020 & $\mathrm{z}_{I 1}$ & 7.01 & $\mathrm{z}_{I 13}$ & 3.61 & $\mathrm{z}_{J 7}$ & -7.54 & $A_{j}$ & 1.0 & & \\
$\xi_{1 R}^{s e}$ & 30.0 & $\zeta_{8}$ & 0.035 & $\mathrm{z}_{I 2}$ & -4.52 & $\mathrm{z}_{I 14}$ & 5.75 & $\mathrm{z}_{J 8}$ & -2.65 & $T$ & 1.0 & & \\
$\xi_{0 P}^{s e}$ & 1.0125 & $\zeta_{9}$ & 0.035 & $\mathrm{z}_{I 3}$ & -4.42 & $\mathrm{z}_{I 15}$ & 0.04 & $\mathrm{z}_{J 9}$ & -2.08 & $N$ & 1.0 & & \\
$\mathrm{z}_{R}$ & 0.0 & $\zeta_{10}$ & 0.035 & $\mathrm{z}_{I 4}$ & -1.14 & $\mathrm{z}_{I 16}$ & 0.92 & $\mathrm{z}_{J 10}$ & -0.80 & $F$ & 0.0 & & \\
\hline
\end{tabular}

Notes: Capital shares are assumed to be constant across zones for both firms $(\delta=0.3)$ and developers $(\theta=0.3)$. Volume delay function parameters are constant across all (road and rail) links; this is a weak assumption because all links represent large parts of a highway system which, at this level of aggregation, is relatively homogenous. Total factor productivity is uniform over space: differences in factor employment (including job concentration) and output level are generated through non-uniform cost shares $(\zeta)$ of the assembly industry. This prevents wages from displaying a spatial variation that would be incompatible with data.

Table C2. Land endowment $(\bar{X})$ of each zone

\begin{tabular}{cccccccccccccccccc}
\hline 1 & 2 & 3 & 4 & 5 & 6 & 7 & 8 & 9 & 10 & 11 & 12 & 13 & 14 & 15 & 16 & 17 & 18 \\
.208 & .222 & .068 & .223 & .158 & .095 & .127 & .140 & .363 & .126 & .206 & .233 & .378 & .082 & .204 & .236 & .208 & .187
\end{tabular}

Notes: Surface endowments are in accordance with the municipal aggregations displayed in Figure 2.

\section{Appendix D: auxiliary notes and steps in the proof of proposition A}

\section{Auxiliary note 1:}

$$
\begin{array}{r}
\frac{\mathrm{d} u}{\mathrm{~d} \tau_{R x}}=\frac{\lambda_{\mathbf{a}} \cdot\left(T_{F \mathbf{a}}-T\right)}{\overline{t_{L}}+}+t_{\mathbf{a}} \\
=-\lambda_{\mathbf{a}} \cdot D_{W \mathbf{a}} \cdot\left(\frac{\mathrm{d} \tau_{L}}{\mathrm{~d} \tau_{R x}} \cdot w_{\mathbf{a}}+I_{r x}+v_{\mathbf{a}} \cdot \frac{\mathrm{d} t_{\mathbf{a}}}{\mathrm{d} \tau_{R x}}\right)= \\
\left.=w_{\mathbf{a}}+I_{r x}+v_{\mathbf{a}} \cdot \frac{\mathrm{d} t_{\mathbf{a}}}{\mathrm{d} \tau_{R x}}\right)
\end{array}
$$

Auxiliary note 2: Decomposition of the total labor supply (in working days) 


$$
\begin{gathered}
\sum_{\mathbf{a}} \frac{\mathrm{d}\left(P_{\mathbf{a}} D_{W \mathbf{a}}\right)}{\mathrm{d} \tau_{R x}}=\sum_{\mathbf{a}} P_{\mathbf{a}} \cdot \frac{\mathrm{d} D_{W \mathbf{a}}}{\mathrm{d} \tau_{R x}}+\sum_{\mathbf{a}} \frac{\mathrm{d} P_{\mathbf{a}}}{\mathrm{d} \tau_{R x}} \cdot D_{W \mathbf{a}}= \\
=\sum_{\mathbf{a}} P_{\mathbf{a}} \cdot\left(\tilde{L}_{\mathbf{a} x}+\frac{\partial D_{W \mathbf{a}}}{\partial \tau_{L}} \frac{\mathrm{d} \tau_{L}}{\mathrm{~d} \tau_{R x}}\right)+\sum_{\mathbf{a}}\left(\sum_{\mathbf{b}} \frac{\partial P_{\mathbf{a}}}{\partial V_{\mathbf{b}}} \cdot \tilde{V}_{\mathbf{b} x}+\frac{\mathrm{d} \tau_{L}}{\mathrm{~d} \tau_{R x}} \cdot \sum_{\mathbf{b}} \frac{\partial P_{\mathbf{a}}}{\partial V_{\mathbf{b}}} \cdot \frac{\partial V_{\mathbf{b}}}{\partial \tau_{L}}\right) \cdot D_{W \mathbf{a}}= \\
=\sum_{\mathbf{a}} P_{\mathbf{a}} \tilde{L}_{\mathbf{a} x}+\frac{\mathrm{d} \tau_{L}}{\mathrm{~d} \tau_{R x}} \sum_{\mathbf{a}} P_{\mathbf{a}} \frac{\partial D_{W \mathbf{a}}}{\partial \tau_{L}}+\sum_{\mathbf{a}} D_{W \mathbf{a}}\left(\sum_{\mathbf{b}} \frac{\partial P_{\mathbf{a}}}{\partial V_{\mathbf{b}}} \cdot \tilde{V}_{\mathbf{b} x}\right)+\frac{\mathrm{d} \tau_{L}}{\mathrm{~d} \tau_{R x}} \sum_{\mathbf{a}} D_{W \mathbf{a}}\left(\sum_{\mathbf{b}} \frac{\partial P_{\mathbf{a}}}{\partial V_{\mathbf{b}}} \cdot \frac{\partial V_{\mathbf{b}}}{\partial \tau_{L}}\right)
\end{gathered}
$$

Auxiliary step A: Consider the following substitutions:

$$
\begin{gathered}
\omega_{1 A x}=-\sum_{\mathbf{a}} P_{\mathbf{a}} D_{W \mathbf{a}} I_{q x} \\
\omega_{1 B x}=-\tau_{L} \sum_{\mathbf{a}} w_{\mathbf{a}} \Xi_{\mathbf{a} x} \\
\omega_{1 C x}=-\sum_{\mathbf{a}}\left(\tau_{R \mathbf{a}} \Xi_{\mathbf{a} x}\right) \\
\omega_{2 A}=\sum_{\mathbf{a}} P_{\mathbf{a}} D_{W \mathbf{a}} w_{\mathbf{a}} \\
\omega_{2 B}=\sum_{\mathbf{a}}\left(\tau_{L} w_{\mathbf{a}}+\tau_{R \mathbf{a}}\right) \Xi_{\mathbf{a}}^{L} \\
\Omega_{1 x}=\omega_{1 A x}+\omega_{1 B x}+\omega_{1 C x}
\end{gathered}
$$

Then, (34) can be written as:

$$
\frac{\mathrm{d} \tau_{L}}{\mathrm{~d} \tau_{R x}}=\frac{\Omega_{1 x}}{\omega_{2 A}+\omega_{2 B}}
$$

and from (35) that:

$$
M_{L}=-\frac{\omega_{2 B}}{\omega_{2 A}+\omega_{2 B}} \Leftrightarrow \omega_{2 A}+\omega_{2 B}=-\frac{\omega_{2 B}}{M_{L}} \Leftrightarrow 1+\frac{\omega_{2 A}}{\omega_{2 B}}=-\frac{1}{M_{L}} \Leftrightarrow \frac{\omega_{2 A}}{\omega_{2 B}}=-\left(\frac{1+M_{L}}{M_{L}}\right) .
$$

From the last two expressions it follows that:

$$
\frac{\mathrm{d} \tau_{L}}{\mathrm{~d} \tau_{R x}}=-\frac{M_{L} \Omega_{1 x}}{\omega_{2 B}}
$$

Auxiliary step B: Using Auxiliary step A, it then holds that:

$$
\frac{\mathrm{d} \tau_{L}}{\mathrm{~d} \tau_{R x}} \sum_{\mathbf{a}} P_{\mathbf{a}} D_{W \mathbf{a}} w_{\mathbf{a}}=-\frac{M_{L} \Omega_{1 x}}{\omega_{2 B x}} \cdot \omega_{2 A}=M_{L} \Omega_{1 x}\left(\frac{1+M_{L}}{M_{L}}\right)=\Omega_{1 x}\left(1+M_{L}\right)
$$

Second-best road taxes in polycentric networks with distorted labor markets 


$$
\begin{aligned}
& =\left(\omega_{1 A x}+\omega_{1 B x}+\omega_{1 C x}\right)\left(1+M_{L}\right) \\
& =\omega_{1 A x}+\omega_{1 A x} M_{L}+\left(\omega_{1 B x}+\omega_{1 C x}\right)\left(1+M_{L}\right) .
\end{aligned}
$$

Using the above together with $\sum_{\mathbf{a}} P_{\mathbf{a}} D_{W \mathbf{a}} I_{q x}=-\omega_{1 A x}$ yields:

$$
\begin{gathered}
\left(\frac{\mathrm{d} \tau_{L}}{\mathrm{~d} \tau_{R x}} \sum_{\mathbf{a}} P_{\mathbf{a}} D_{W \mathbf{a}} w_{\mathbf{a}}\right)+\sum_{\mathbf{a}} P_{\mathbf{a}} D_{W \mathbf{a}} I_{r x}=\omega_{1 A x} M_{L}+\omega_{1 B x}\left(1+M_{L}\right)+\omega_{1 C x}\left(1+M_{L}\right) \\
=\left(\omega_{1 A x}+\omega_{1 C x}\right) M_{L}+\omega_{1 B x}\left(1+M_{L}\right)+\omega_{1 C x} .
\end{gathered}
$$

Auxiliary step C: Now, decompose the total toll cost of route $q$ embodied in alternative $\mathbf{a}=\{i, j, q\}$ using:

$$
\tau_{R \mathbf{a}}=\left(\tau_{R x} I_{q x}+\sum_{l \neq x}\left(\tau_{R l} I_{q l}\right)\right)
$$

Then, developing further the term $\omega_{1 C x}$, yields:

$$
\omega_{1 C x}=-\sum_{\mathbf{a}}\left(\tau_{R \mathbf{a}} \Xi_{\mathbf{a} x}\right)=-\sum_{l}\left(\tau_{R l} \sum_{\mathbf{a}} I_{q l} \Xi_{\mathbf{a} x}\right)=-\sum_{l}\left(\tau_{R l} \tilde{L}_{l x}\right)
$$

where:

$$
\tilde{L}_{l x}=\sum_{\mathbf{a}} I_{q l} \Xi_{\mathbf{a x}}
$$

is the portion of total change in the load of link $l$ occurring through adjustment of all endogenous variables except for the labor tax $\tau_{L}$. Then:

$$
\omega_{1 C x}=-\sum_{l}\left(\tau_{R l} \cdot \tilde{L}_{l x}\right)=-\tau_{R x} \tilde{L}_{x x}-\sum_{l \neq x}\left(\tau_{R l} \tilde{L}_{l x}\right)
$$

Developing the last term of the sum in (38), i.e. $\mathcal{P}$, yields:

$$
\sum_{\mathbf{a}} P_{\mathbf{a}} v_{\mathbf{a}} D_{W \mathbf{a}} \frac{\mathrm{d} t_{\mathbf{a}}}{\mathrm{d} \tau_{R x}}=\sum_{l}\left(\frac{\mathrm{d} t_{l}}{\mathrm{~d} \tau_{R x}}\left(\sum_{\mathbf{a}} P_{\mathbf{a}} v_{\mathbf{a}} D_{W \mathbf{a}} I_{q l}\right)\right)=\sum_{l}\left(t_{l}^{\prime} \cdot \tilde{L}_{l x} \cdot\left(\sum_{\mathbf{a}} P_{\mathbf{a}} v_{\mathbf{a}} D_{W \mathbf{a}} I_{q l}\right)\right),
$$

where the first equality exploits the fact that the aggregate value of time gains or losses in the network, caused by the adjustment of road tax $\tau_{R x}$, should not depend on whether the aggregation takes place across routes or links. Using (19), the latter expression becomes:

$$
\sum_{\mathbf{a}} P_{\mathbf{a}} v_{\mathbf{a}} D_{W \mathbf{a}} \frac{\mathrm{d} t_{\mathbf{a}}}{\mathrm{d} \tau_{R x}}=\sum_{l}\left(\tilde{L}_{l x} \cdot \operatorname{mecc}_{l}\right)=\left(\tilde{L}_{x x} \cdot \operatorname{mecc}_{x}+\sum_{l \neq x}\left(\tilde{L}_{l x} \cdot \operatorname{mecc}_{l}\right)\right) .
$$

Second-best road taxes in polycentric networks with distorted labor markets 
Finally:

$$
\sum_{\mathbf{a}} P_{\mathbf{a}} v_{\mathbf{a}} D_{W \mathbf{a}} \frac{\mathrm{d} t_{\mathbf{a}}}{\mathrm{d} \tau_{R x}}+\omega_{1 C x}=\tilde{L}_{x x} \cdot\left(\operatorname{mecc}_{x}-\tau_{R x}\right)+\sum_{l \neq x} \tilde{L}_{l x} \cdot\left(m e c c_{l}-\tau_{R l}\right)
$$

and:

$$
\begin{aligned}
\left(\frac{\mathrm{d} \tau_{L}}{\mathrm{~d} \tau_{R x}} \sum_{\mathbf{a}} P_{\mathbf{a}} D_{W \mathbf{a}} W_{\mathbf{a}}\right)+\sum_{\mathbf{a}} P_{\mathbf{a}} D_{W \mathbf{a}} I_{r x}+\sum_{\mathbf{a}} P_{\mathbf{a}} v_{\mathbf{a}} D_{W \mathbf{a}} \frac{\mathrm{d} t_{\mathbf{a}}}{\mathrm{d} \tau_{R x}} \\
=\left(\sum_{l}\left(\tilde{L}_{l x} \cdot\left(\operatorname{mecc}_{l}-\tau_{R l}\right)\right)+\left(\omega_{1 A x}+\omega_{1 C x}\right) M_{L}+\omega_{1 B x}\left(1+M_{L}\right)\right) .
\end{aligned}
$$

Multiplying the right hand side with $N$ and negating yields:

$$
\frac{1}{\lambda} \frac{\mathrm{d} W}{\mathrm{~d} \tau_{R x}}=N\left(\sum_{l}\left(\tilde{L}_{l x} \cdot\left(\tau_{R l}-\operatorname{mecc}_{l}\right)\right)-\left(\omega_{1 A x}+\omega_{1 C x}\right) M_{L}-\omega_{1 B x}\left(1+M_{L}\right)\right) .
$$

Substituting back the $\omega$ terms yields (21), which proves Proposition A. 


\section{References}

Acutt, A.Z., Dodgson, J.S., 1996. Cross-elasticities of demand for travel. Transport Policy, 4 (2), 271 277.

Anas, A., 2012. The optimal pricing, finance, and supply of urban transportation in general equilibrium: a theoretical exposition. Economics of Transportation, 1, 64-76.

Anas, A., Hiramatsu, T., 2012. The effect of the price of gasoline on the urban economy: from route choice to general equilibrium. Transportation Research Part A, 46, 855-873.

Anas, A., Hiramatsu, T., 2013. The economics of cordon tolling: general equilibrium and welfare analysis. Economics of Transportation, 2 (1), 18-37.

Anas, A., Kim, I., 1996. General equilibrium models of polycentric urban land use with endogenous congestion and job agglomeration. Journal of Urban Economics, 40 (2), 232-256.

Anas, A., Liu, Y., 2007. A regional economy, land use, and transportation model (RELU-TRAN): formulation, algorithm design, and testing. Journal of Regional Science, 47 (3), 415-455.

Anas, A., Pines, D., 2012. Public goods and congestion in a system of cities: how do fiscal and zoning policies improve efficiency? Journal of Economic Geography, 4, 649-676.

Anas, A., Xu, R., 1999. Congestion, land use, and job dispersion: a general equilibrium model. Journal of Urban Economics, 45 (3), 451-473.

Bento, A.M, Franco, S.F., Kaffine, D., 2011. Is there a double-dividend from anti-sprawl policies? Journal of Environmental Economics and Management, 61 (2), 135-152.

Bovenberg, A.L., 1999. Green tax reforms and the double dividend: an updated reader's guide. International Tax and Public Finance, 6, 421-443.

Bovenberg, A.L., de Mooij, R.A., 1994. Environmental levies and distortionary taxation. American Economic Review, 84 (4), 1085-1089.

Bovenberg, A.L., Goulder, L.H., 1996. Optimal environmental taxation in the presence of other taxes: general equilibrium analyses. American Economic Review, 86 (4), 985-1000.

Broersma, L., van Dijk, J., 2008. The effect of congestion and agglomeration on multifactor productivity growth in Dutch regions. Journal of Economic Geography, 8, 181-209.

Dagsvik, J.K., Karlström, A., 2005. Compensating variation and hicksian choice probabilities in random utility models that are nonlinear in income. Review of Economic Studies, 72 (1), 57-76.

De Borger, B., 2009. Commuting, congestion tolls and the structure of the labour market: Optimal congestion pricing in a wage bargaining model. Regional Science and Urban Economics, 39, 434-448.

Dröes, M.I., Rietveld, P., 2015. Rail-based public transport and urban spatial structure: The interplay between network design, congestion and urban form. Transportation Research Part B, 81, 421-439.

Dimitropoulos, A., Oueslati, W., Sintek, C., 2016. The rebound effect in road transport: a meta-analysis of empirical studies, OECD Environment Working Papers, No. 113, OECD Publishing, Paris. http://dx.doi.org/10.1787/8516ab3a-en 
Evers, M., De Mooij, R., Van Vuuren, D., 2008. The wage elasticity of labor supply: A synthesis of empirical estimates. De Economist, 156 (1), 25-43.

Goodwin, P., Dargay, J., Hanly, M., 2004. Elasticities of road traffic and fuel consumption with respect to price and income: a review. Transport Reviews, 24 (3), 275-292.

Goulder, L.H., 1995. Environmental taxation and the double dividend: a reader's guide. International Tax and Public Finance, 2, 157-183.

Goulder, L.H., Parry, I.W.H., Williams, R.C., Burtraw, D., 1999. The cost-effectiveness of alternative instruments for environmental protection in a second-best setting. Journal of Public Economics, 72 (3), 329-360.

Hansson, I., Stuart, C., 1985. Tax revenue and the marginal cost of public funds in Sweden. Journal of Public Economics, 27, 331-353.

Herriges, J.A., Cling, C.L., 1999. Non-linear income effects in random utility models. The review of Economics and Statistics, 81 (1), 62-72.

Hirte, G. and S. Tscharaktschiew, 2013. The optimal subsidy on electric vehicles in German metropolitan areas: A spatial general equilibrium analysis. Energy Economics, 40, 515-528.

Hirte, G., Tscharaktschiew, S., 2015. Does labor supply modeling affect findings of transport policy analyses? Dresden Discussion Paper Series in Economics 01/15.

Jacobs, B., de Mooij, R.A., 2015. Pigou meets Mirrlees: On the irrelevance of taks distortions for the second-best Pigouvian tax. Journal of Environmental Economics and Management, 71, 90-108.

Kono, T., Kawaguchi, H., 2016. Cordon pricing and land use regulation. Forthcoming in Scandinavian Journal of Economics, doi/10.1111/sjoe.12167/abstract.

Lucas, R., Rossi-Hansberg, E., 2002. On the internal structure of cities. Econometrica, 70, 1445-1476.

Mun, S., Konishi, K., Yoshikawa, K., 2003. Optimal cordon pricing. Journal of Urban Economics, 54, 21-38.

Mun, S., Konishi, K., Yoshikawa, K., 2005. Optimal cordon pricing in a non-monocentric city. Transportation Research Part A, 39 (7-9), 723-736.

U.S. Department of Transportation, Federal Highway Administration, 2004. National Household Travel Survey 2001. User's guide. National sample with add-ons. Available at: http://nhts.ornl.gov/index.shtml.

OECD, 2007. Territorial Review: Randstad Holland, Netherlands.

OECD (2017), Harmonised unemployment rate (HUR) (indicator). doi: 10.1787/52570002-en (Accessed on 08 September 2017).

Parry, I.W.H., 1995. Pollution taxes and revenue recycling. Journal of Environmental Economics and Management, 29 (3), 64-77.

Parry, I.W.H., 2002. Comparing the efficiency of alternative policies for reducing traffic congestion. Journal of Public Economics, 85 (3), 333-362.

Second-best road taxes in polycentric networks with distorted labor markets 
Parry, I.W.H., Bento, A.M., 2000. Tax deductions, environmental policy and the "double-dividend" hypothesis. Journal of Environmental Economics and Management, 39 (1), 67-96.

Parry, I.W.H., Bento, A.M., 2001. Revenue recycling and the welfare effects of road pricing. Scandinavian Journal of Economics, 103 (4), 645-671.

Parry, I.W.H., Bento, A.M., 2002. Estimating the welfare effects of congestion taxes: the critical importance of other distortions within the transport system. Journal of Urban Economics, 51 (2), 339365.

Rhee, H.J., Yu, S., Hirte, G., 2014. Zoning in cities with traffic congestion and agglomeration externalities. Regional Science and Urban Economics, 44, 82-93.

Schwanen, T., Dieleman, F.M., Dijst, M., 2001. Travel behaviour in Dutch monocentric and polycentric systems. Journal of Transport Geography, 9 (3), 173-186.

Small, K., 2012. Valuation of travel time. Economics of transportation, 1 (1-2), 2-14.

Tikoudis, I., Verhoef, E.T., van Ommeren, J.N., 2015. On revenue recycling and the welfare effects of second-best congestion pricing in a monocentric city. Journal of Urban Economics, 89, 32-47.

Tikoudis, I., Verhoef, E.T., van Ommeren, J.N., 2015. Second-best urban tolls in a monocentric city with housing market regulations. Tinbergen Institute discussion paper: TI 2015-006/VIII.

Tscharaktschiew, S., Hirte, G., 2010. The drawbacks and opportunities of carbon charges in metropolitan areas - A spatial general equilibrium approach. Ecological Economics, 70, 339-357.

Van Dender, K., 2003. Transport taxes with multiple trip purposes. Scandinavian Journal of Economics, 105 (2), 295-310.

Van Dender, K., 2004. Pricing transport networks with fixed residential location. Regional Science and Urban Economics, 34 (3), 289-307.

Verhoef, E.T., Nijkamp, P., Rietveld, P., 1996. Second best congestion pricing: the case of an untolled alternative. Journal of Urban Economics, 40 (3), 279-302.

Verhoef, E.T.., 2002a. Second-best congestion pricing in general networks. Heuristic algorithms for finding second-best optimal toll levels and toll points. Transportation Research Part B, 36 (8), 707-729.

Verhoef, E.T., 2002b. Second-best congestion pricing in general static transportation networks with elastic demands. Regional Science and Urban Economics, 32 (3), 281-310.

Verhoef, E.T., 2005. Second-best congestion pricing schemes in the monocentric city. Journal of Urban Economics, 58 (3), 367-388.

Second-best road taxes in polycentric networks with distorted labor markets 